\title{
Los nahuas de Tzintzuntzan-Huitzitzilan, Michoacán: historia, mito y legitimación de un señorío prehispánico
}

\section{Hans Roskamp}

\section{OpenEdition}

\section{Journals}

Edición electrónica

URL: https://journals.openedition.org/jsa/11264

DOI: 10.4000/jsa. 11264

ISSN: $1957-7842$

Editor

Société des américanistes

Edición impresa

Fecha de publicación: 5 junio 2010

Paginación: 75-106

ISSN: 0037-9174

\section{Referencia electrónica}

Hans Roskamp, «Los nahuas de Tzintzuntzan-Huitzitzilan, Michoacán: historia, mito y legitimación de un señorío prehispánico», Journal de la Société des américanistes [En línea], 96-1 | 2010, Publicado el 10 diciembre 2014, consultado el 02 septiembre 2022. URL: http://journals.openedition.org/jsa/11264 DOI: https://doi.org/10.4000/jsa.11264 


\title{
LOS NAHUAS \\ DE TZINTZUNTZAN-HUITZITZILAN, MICHOACÁN. HISTORIA, MITO Y LEGITIMACIÓN DE UN SEÑORÍO PREHISPÁNICO
}

\author{
Hans ROSKAMP *
}

La historiografía moderna sobre el Michoacán de fines del siglo xv y principios del siglo Xvi enfatiza el éxito político-económico de los tarascos y de su principal linaje uacúsecha pero dedica relativamente poca atención a los demás grupos étnicos que radicaban en la región. Este artículo trata de la naturaleza y fuerza de las tradiciones históricas nahuas de Michoacán, con especial atención para el caso de TzintzuntzanHuitzitzilan, lugar que al momento de la conquista española era la capital del señorío uacúsecha. La presencia de los nahuas y su interacción con los tarascos no sólo llegaron a formar parte de las diversas visiones locales del pasado sino también tal vez hayan influido las miradas históricas de los vecinos nahuas del occidente y centro de México, quienes en sus narraciones de origen, migración y establecimiento de sus propios señoríos frecuentemente establecían una relación directa con el poblamiento de Michoacán. Estas tradiciones históricas claramente cumplen fines de legitimación y constituyen una compleja mezcla de registros de determinados sucesos, representaciones cosmológicas, así como símbolos religiosos y políticos. [Palabras claves: Michoacán, tarascos, nahuas, mitos, tradiciones históricas indígenas, origen, migración, fundación, legitimación, identidad.]

Les Nahua de Tzintzuntzan-Huitzitzilan, Michoacán: histoire, mythe et légitimation d'une seigneurie préhispanique. L'historiographie moderne sur le Michoacán de la fin du $\mathrm{Xv}^{\mathrm{e}}$ siècle et du début du $\mathrm{Xvl}^{\mathrm{e}}$ siècle accorde beaucoup d'importance au succès politicoéconomique des Tarasques et de leur lignage principal uacúsecha. En revanche, elle consacre relativement peu d'attention aux autres groupes ethniques qui habitaient la région. Cet article traite de la nature et de la force des traditions historiques nahua du Michoacán, particulièrement celles de Tzintzuntzan-Huitzitzilan, capitale de la seigneurie uacúsecha. La présence des Nahua et leur interaction avec les Tarasques font non seulement partie des diverses visions locales du passé, mais ont aussi probablement

\footnotetext{
* El Colegio de Michoacán, Martínez de Navarrete 505, CP. 59699 Zamora, Michoacán, México [Roskamp@colmich.edu.mx]
}

Journal de la Société des Américanistes, 2010, 96-1, pp. 75-106. O Société des Américanistes. 
influé sur les vues historiques des voisins nahua de l'ouest et du centre du Mexique. Ces derniers établissaient fréquemment, dans les narrations d'origine, de migration et de fondation de leurs seigneuries, une relation directe avec le peuplement du Michoacán. Ces traditions historiques avaient clairement une intention de légitimation et constituent un mélange complexe de registres de faits précis, de représentations cosmologiques, ainsi que de symboles religieux et politiques. [Mots-clés: Michoacán, Tarasques, Nahua, mythes, traditions historiques indigènes, origine, fondation, migration, légitimation, identité.]

The Nahuas of Tzintzuntzan-Huitzitzilan, Michoacán: history, myth and legitimization of a Prehispanic señorío. Modern historiography on 15th and early 16th century Michoacán emphasizes the political-economical success of the Tarascans and their uacúsecha lineage but pays relatively little attention to other ethnic groups that lived in the region. This article deals with the nature and strength of the historical traditions of the Nahuas in Michoacán, paying special attention to the case of TzintzuntzanHuitzitzilan, a place which at the time of the Spanish conquest was the capital of the uacuisecha señorio. The presence of the Nahuas and their interaction with the Tarascans not only became part of the diverse local visions of the past but possibly also influenced the historical views of the Nahua neighbors from West and Central México. The latter frequently established a direct relation with the population of Michoacán in narratives about origin, migration and foundation of their own señorios. These historical traditions clearly served the purpose of legitimization and constitute a complex blend of registered events, cosmological representations, as well as religious and political symbolism. [Key words: Michoacán, Tarascans, Nahuas, myths, indigenous historical traditions, foundation, migration, legitimization, identity.]

\section{INTRODUCCIÓN}

A partir de un interesante enfoque interdisciplinario, hace casi una década el arqueólogo Leonardo López Luján y el historiador Alfredo López Austin señalaron que, entre los siglos vII y XVI, varias partes de la región cultural mesoamericana experimentaron un proceso histórico de suma complejidad a que ambos se refieren como la implementación del sistema zuyuano:

Su eje fue de carácter político, y consistió fundamentalmente en una reorganización estatal que comprendía la creación de gobiernos supraétnicos que aglutinaban unidades de diversas etnias; el establecimiento de un dominio regional a través de confederaciones de capitales hegemónicas, y la implementación de regímenes militaristas encargados de mantener y expandir el orden político y económico. (López Austin y López Luján 1999, p. 141)

La característica principal del mencionado sistema, a que otros prefieren referirse con el uso del término « tolteca » (Navarrete Linares 2000, p. 18), es la implementación de una estructura gubernamental que respetaba el orden político 
y el sustento ideológico interno de todas las unidades étnicamente diferenciadas. La legitimidad de los gobiernos étnicos ni su fundamento religioso fueron cuestionados sino únicamente asimilados por una estructura gubernamental sobrepuesta que era de índole supraétnica e incluso tenía su propio dios patrono (López Austin y López Luján 1999, p. 42).

Si bien se desconoce el origen concreto del llamado sistema zuyuano, hay amplia evidencia de que mediante migraciones, conquistas y redes comerciales llegó a difundirse e implementarse en el centro de México, Oaxaca, el norte de Yucatán y los Altos de Guatemala (ibid., p. 38). Los autores arriba mencionados también agregaron - de manera acertada - el caso de Michoacán, enfatizando la gran expansión del señorío tarasco a partir de las exitosas campañas militares emprendidas por Tariacuri, señor de Pátzcuaro, y sus sucesores que llegaron a gobernar en forma de una triple alianza: Hiquingaje como señor de Pátzcuaro, Tangaxoan e Hiripan como cabezas de los señoríos de Tzintzuntzan-Huitzitzilan e Ihuatzio respectivamente (para la ubicación de los lugares, véase la Figura 1) ${ }^{1}$. Los últimos tres anexaron múltiples señoríos habitados por grupos étnicamente distintos que a su vez llegaron a fortalecer los ejércitos en acciones tanto ofensivas (expansionistas) como defensivas (cuidando las fronteras). El orden y las costumbres de los señoríos parecen haber sido respetados aunque sí llegaron a formar parte de una nueva estructura estatal con su propio fundamento ideológico. Por lo general los gobernantes locales mantenían su poder pero necesitaban la continua legitimación por parte de los señores uacúsecha (águilas), que conformaban el principal linaje tarasco y eran los máximos representantes del dios estatal Curicaueri (López Austin y López Luján 1999, pp. 135-140).

Aunque a partir del señor Tzitzispandaquare (el hijo de Tangaxoan) al parecer se inició una creciente concentración del poder en TzintzuntzanHuitzitzilan y se desintegró la triple alianza, una situación que por lo menos en parte puede compararse con lo ocurrido en el centro de México (ibid., pp. 74, 135-140), la política al respecto de la diversidad étnica no parece haber sufrido mayores transformaciones y mantuvo su importancia en la formación y reestructuración del estado hasta la llegada de los españoles e inclusive durante la primera parte del dominio colonial. La tradición histórica y la identidad de los grupos no tarascos no fueron reemplazadas sino permanecieron fuertes, situación que se ve claramente reflejada en el Lienzo de Jicalán (o Jucutacato) y la Probanza de Tetlama, documentos elaborados o por lo menos empleados en 1565 y 1577 respectivamente ${ }^{2}$. El primer documento (Figura 2), usado en el contexto de un pleito sobre minas con un asentamiento tarasco, nos relata el origen de unos náhuatl hablantes en un lugar más allá de las costas de Veracruz, donde iniciaron una larga migración a Michoacán para fundar el cacicazgo de Xiuhquilan o Jicalán, guiados por su dios patrono Tezcatlipoca. Este último no sólo asistió a sus seguidores en la búsqueda de minerales sino también les enseñó trabajar la metalurgia del cobre y pintar jícaras (maque). Posteriormente, al momento de ser 


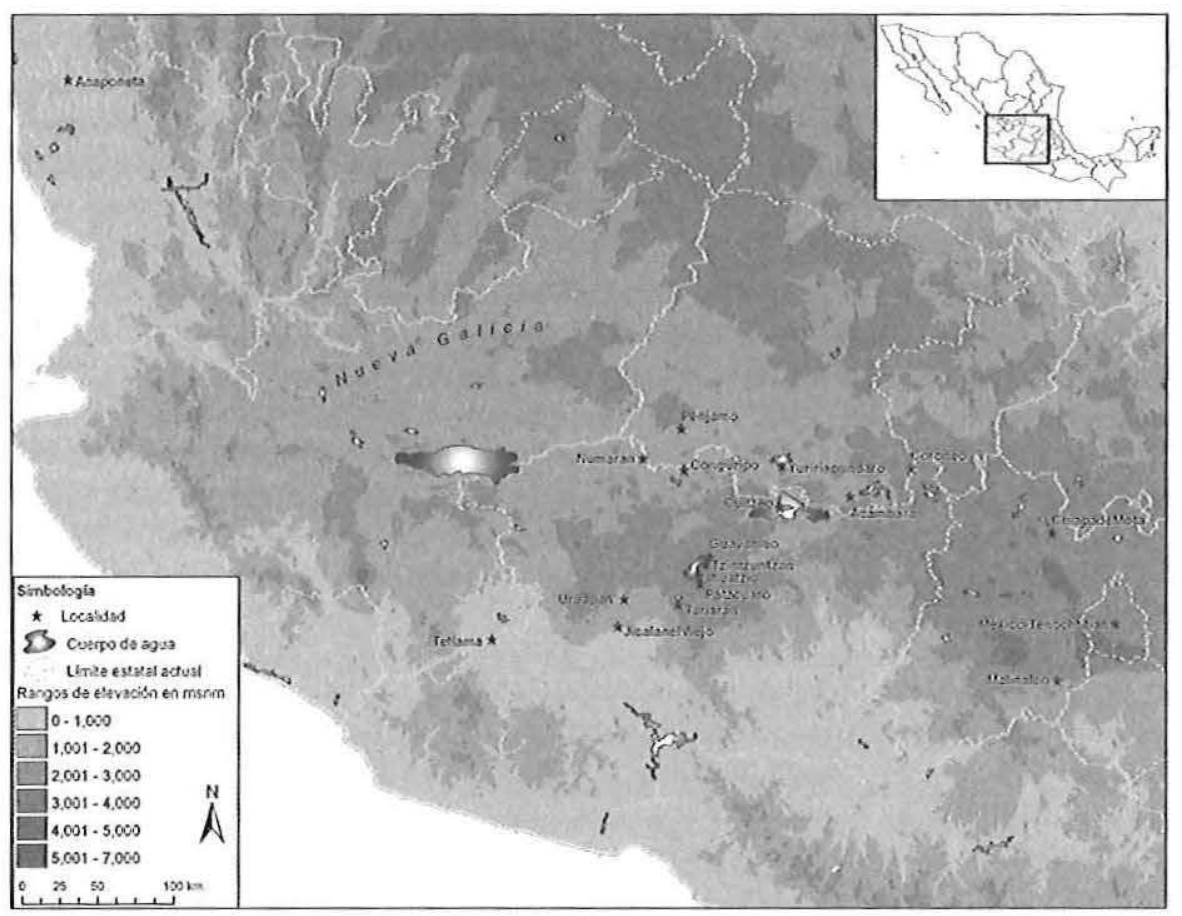

Fig. 1 - Mapa del centro-occidente de México con los principales lugares mencionados en el texto (investigación y elaboración: Marco Antonio Hernández y Hans Roskamp).

incorporados al señorío uacúsecha, sus antiguos derechos sagrados a los recursos naturales fueron reconocidos por los gobernantes en turno, al parecer sobre todo por el señor de Coyoacan-Ihuatzio que era sujeto de Tzintzuntzan-Huitzitzilan. Si bien el documento pictográfico únicamente marca la fundación nahua de Jicalán, al mismo tiempo muestra el contacto directo de los pobladores con una serie de otros asentamientos en la Tierra Caliente de Michoacán, especialmente en el medio Balsas y el área de Tepalcatepec (conocido como cinturón del cobre). La Probanza de Tetlama, que consiste del registro de varios testimonios orales, igualmente se refiere al origen de un grupo de náhuatl hablantes en tierras más allá de la costa veracruzana quienes migraron a Michoacán y finalmente fundaron a Tetlama, donde se dividieron para establecerse también en Atipaqui, Tacasquaro y otros asentamientos que no son especificados. Tiempo después, se ofrecieron voluntariamente como vasallos de los uacúsecha quienes los ocuparon para la defensa de las fronteras de sus dominios (Carrasco 1969; Roskamp 1998, 2001).

Un caso menos conocido es el de la población nahua de TzintzuntzanHuitzitzilan, la capital del señorío uacúsecha al momento de la llegada de los españoles. Según la Memoria de Caltzin, elaborada en 1543 pero refiriéndose al 


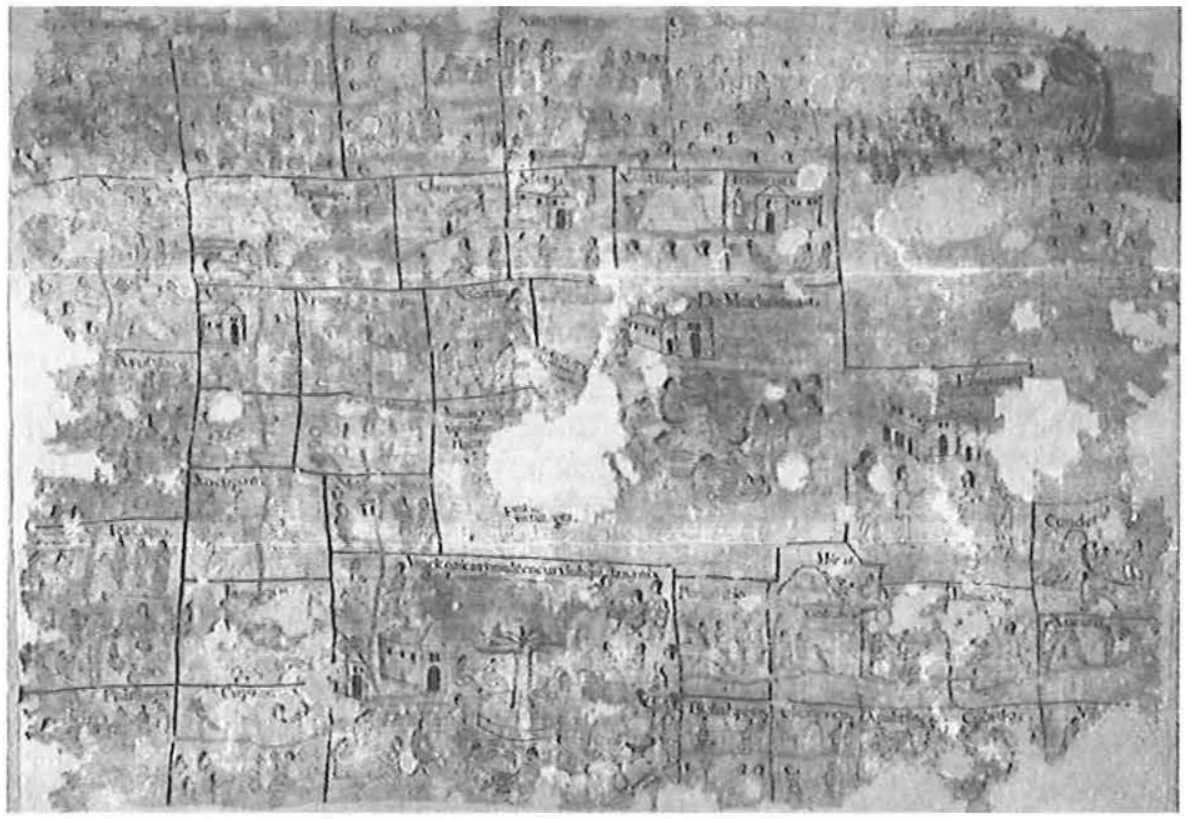

FIG. 2 - El Lienzo de Jicalán (o Jucutacato) que representa el origen y migración del grupo nahua de los xiuhquilteca a Michoacán (imagen reproducida con permiso de la Sociedad Mexicana de Geografia y Estadística).

contenido de un códice más antiguo, fueron veinte mercaderes nahuas que originalmente ayudaron al rey uacúsecha Tzitzispandaquare a conquistar y repoblar a este asentamiento, recibiendo a cambio una serie de derechos y privilegios para ellos y sus descendientes (Monzón, Roskamp y Warren 2009). En el presente texto, el relato de Caltzin constituye el punto de partida para un análisis de otra antigua narración indígena sobre la fundación multiétnica del mismo lugar que se encuentra registrada en la Crónica Miscelánea de la Sancta Provincia de Jalisco, redactada a mediados del siglo XVII por el franciscano Antonio Tello. Este relato nos remite directamente a un tema que es de primordial importancia en las tradiciones históricas indígenas: la propia creación de los diversos grupos humanos en un lugar distante, su peregrinaje y llegada a la tierra prometida, así como el establecimiento de sus poblaciones y señoríos, sucesos atribuidos a la agencia de diversas fuerzas divinas. Estos discursos expresan la identidad del grupo en cuestión y claramente cumplían una función de legitimación política. Sobre todo por su fuerte carga religiosa e ideológica, en la historiografía moderna frecuentemente han sido calificados como mitos y considerados lo opuesto de una historia verificable o por lo menos más objetiva. Sin embargo, aunque este esquema clasificatorio resulta un importante instrumento de análisis 
en la historiografía moderna ${ }^{3}$, es necesario tener en cuenta que los antiguos mesoamericanos no lo manejaban y no distinguían entre estos dos tipos de visiones del pasado. Para ellos fue una historia única y real que explicaba no sólo el origen del mundo en que estaban viviendo y el lugar que ocupaba el propio grupo en relación con los demás, sino también sus propios derechos y privilegios ancestrales ${ }^{4}$.

\section{La memoria de Caltzin: los aliados nahuas de los Uacúsecha}

Cuando en 1538 Tzintzuntzan-Huitzitzilan perdió el estatus de capital de la provincia de Michoacán a favor de Pátzcuaro, se inició una larga lucha por la recuperación de sus antiguos derechos y privilegios que - por lo menos al principio - fue encabezada por la parcialidad de los nahuas cuyo señor principal parece haber sido un tal don Domingo Catsimito (posiblemente Casimiro). Este se enfrentó no sólo al obispo Vasco de Quiroga y al alcalde mayor sino también al gobernador y cacique de Michoacán, don Antonio Huitzimengari, quien era hijo de Tzintzicha Tangaxoan y tenía su sede en Pátzcuaro. Don Domingo fue acusado de desobediencia e inclusive de haber querido asesinar a Huitzimengari cuando éste le solicitó su participación obligatoria en la pacificación de grupos rebeldes (como los Guachichiles) en la Nueva Galicia. El señor de los nahuas fue excomulgado y posteriormente condenado a cinco o seis años de destierro de la provincia (Monzón, Roskamp y Warren 2009, pp. 34-51) ${ }^{5}$.

Además de la fuerza física, testimonios orales y documentos oficiales expedidos por autoridades virreinales, don Domingo también parece haber empleado un códice en el intento de recuperar el poder de Tzintzuntzan-Huitzitzilan y de sus nobles. Aunque el documento original se encuentra perdido, afortunadamente se cuenta con un breve resumen de su contenido en lengua tarasca, cuyo autor fue un escribano que llevaba el apellido nahua Caltzin. El mencionado documento pictográfico y su resumen claramente constituyen una probanza no sólo del estatus del antiguo señorío sino sobre todo de los méritos de los nahuas que participaron en la conquista del lugar por el señor Tzitzispandaquare. En otras palabras podemos decir que la documentación alude a un pacto original entre los uacúsecha y los nahuas que por su participación militar recibieron varios derechos y privilegios como señores de Tzintzuntzan-Huitzitzilan, en especial el acceso a tributarios y tierras (Monzón, Roskamp y Warren 2009, pp. 34-51).

En la propia tradición histórica de los uacúsecha, que fue registrada en la Relación de Michoacán (Alcalá 2000) ${ }^{6}$, se menciona que la ocupación del señorío de Tzintzuntzan-Huitzitzilan estuvo a cargo del señor Tangaxoan, el padre de Tzitzispandaquare, sin tocar el tema de una participación por parte de los nahuas. Sin embargo, es posible que la presencia de este último grupo esté referida más 
bien de manera indirecta a través del énfasis en la importancia de la diosa Xaratanga quien se manifestó en un sueño a Tangaxoan y pidió que este la llevara a Tzintzuntzan-Huitzitzilan y ocupara el trono (Alcalá 2000, pp. 494-500, 541543). Ella ya había estado en el lugar pero lo había abandonado algún tiempo antes del nacimiento de Tariacuri para irse al sur y finalmente establecerse en un sitio llamado Tariaran. La causa del abandono fue el castigo que la misma deidad propinó a dos de sus sacerdotes, así como a dos hermanas de ellos, convirtiéndolos a los cuatro en culebras por haberse burlado de ella en el día de su fiesta. Este suceso fue interpretado como un agüero no sólo por los otros servidores de Xaratanga sino también por los grupos de uacúsecha (en aquel entonces asentados en Guayameo) que se dividieron, tomaron a sus dioses patronos y se establecieron cada uno en un lugar diferente (ibid., pp. 350-352).

Posteriormente, cuando Tariacuri gobernaba el señorío uacúsecha desde Pátzcuaro y el señor de Tariaran (Zurunban) era su suegro, este último ofreció ayuda a la isla de Xaracuaro que era atacada por los uacúsecha. Mandó a uno de sus sacerdotes (posiblemente representante de Xaratanga) a juntar un ejército pero fracasó en el intento. El emisario religioso fue capturado, ejecutado, cocido y ofrecido como alimento a su propio superior (ibid., pp. 376-394). Naca, el nombre del desafortunado, parece derivarse del náhuatl "nacatl » (carne) y podría indicar su pertenencia al grupo que hablaba esta lengua. Tal vez no sea casual que Hiuacha, el último señor independiente de Tariaran, buscara refugio precisamente en los asentamientos vecinos que contaban con población nahua. También habría que mencionar que el mismo señor empleaba el tonalpohualli (la cuenta de los días) para planear sus actividades militares, una costumbre que no era compartida por los uacúsecha, lo que podría indicar diferencias culturales entre los grupos nahuas y tarascos (ibid., pp. 509-518). Por lo tanto es probable que Tariaran pueda incluirse en la lista de poblaciones michoacanas con presencia nahua y que al mismo tiempo exista una clara asociación entre este grupo étnico y la diosa Xaratanga. Si esto fuera correcto, podría ser una fuerte indicación de que también Tzintzuntzan-Huitzitzilan originalmente fuera dominado por grupos nahuas ya que de este lugar salieron los fundadores de Tariaran y la diosa Xaratanga que posteriormente volvió como diosa tutelar de los uacúsecha. Ampliando esta hipótesis, que parte exclusivamente de información proporcionada en la Relación de Michoacán, implicaría que en el gobierno de Tangaxoan o Tzitzispandaquare los uacúsecha se apoderaron de la tradición religiosa correspondiente a la diosa Xaratanga, así como de su antiguo lugar de culto.

Aunque la Relación... enfatiza principalmente los méritos del grupo uacúsecha que estaba en el poder $\mathrm{y}$ - como vimos - no contiene una referencia directa a los nahuas prehispánicos de Tzintzuntzan-Huitzitzilan, sí menciona que la región originalmente estaba poblada por grupos tanto tarascos como nahuas, información importante que el fraile Alcalá resumía de la siguiente manera ${ }^{7}$ : 
[...] lo que se colige desta historia es que los antecesores del caçonçi [el irecha o rey uacúsecha] vinieron a la postre a conquistar esta tierra y fueron señores della. Extendieron su señorio y conquistaron esta Provincia que estaba primero poblada de gente mexicana, naguatatos, y de su misma lengua; que parece que otros señores vinieron primero y había en cada pueblo su cacique con su gente y sus dioses por sí. Y como la conquistaron hicieron un reino de todo, desde el bisagüelo del caçonzi pasado que fue señor en Michuacan, como se dirá en otra parte. (Alcalá 2000, p. 341) ${ }^{8}$

Es probable que el autor franciscano de la Relación... haya derivado su apreciación directamente de las pocas referencias a poblaciones prehispánicas de identidad nahua en la historia oficial de los uacúsecha que él mismo recopiló y posteriormente anotó en lengua española. La mención más evidente nos remite a los reyes Hiripan, Tangaxoan y Hiquingaje quienes lograron conquistar a los asentamientos nahuas (no identificados) de Hacauato, Zizupan, Chenengo, Vacapu (todos al sur de Uruapan) y Cupuan, este último en el medio Balsas (Alcalá 2000, pp. 519, 524) ${ }^{9}$. Tampoco se puede olvidar el episodio de la muerte de Vapeani, hermano de Pauacume, en el monte de Çacapu hacurua (cerca de Pátzcuaro), que es descrito como un lugar « donde moran los naguatatos » (ibid., p. 371) ${ }^{10}$. La fuente también reporta la existencia de nahuas que eran aprovechados por el rey uacúsecha como intérpretes para la comunicación con las embajadas del rey Montezuma de México-Tenochtitlan, quien buscaba una alianza con los tarascos en contra de la amenaza de la invasión española (Alcalá 2000, pp. 651-652). Además, nos remite a Juan de Ortega, « un señor de los nabatlatos » (nahuas), que se encontraba entre un grupo de nobles que - junto con el rey uacúsecha Tzintzicha Tangaxoan - fueron torturados por Nuño de Guzman en Tzintzuntzan-Huitzitzilan, en 1531 (ibid., p. 687) ${ }^{11}$. Finalmente, cabe aclarar que la fuente también menciona - sin dar mayores explicaciones - algunos nombres en lengua náhuatl, los cuáles en sí no constituyen ninguna evidencia de que sus usuarios hayan pertenecido a este grupo no tarasco ${ }^{12}$.

Es interesante observar que el comentario en la Relación de Michoacán sobre la antigüedad de grupos tarascos y nahuas en la región, así como la llegada posterior de los uacúsecha, coincide con la información encontrada en dos documentos de la propia tradición histórica nahua, ya mencionados con anterioridad: el Lienzo de Jicalán y la Probanza de Tetlama. Ambos no sólo argumentan que los grupos nahuas se establecieron en múltiples lugares del centro-sur de Michoacán antes de llegar a ser tributarios de los uacúsecha sino además especifican que las relaciones se establecieron de manera voluntaria y pacífica. Cabe agregar que los pobladores de Tetlama, igual que otros grupos no tarascos ubicados en las fronteras, incluso recibieron un papel militar al servicio del señorío uacúsecha. La Relación de Michoacán y otras fuentes enfatizan el carácter forzado y jerárquico de estas relaciones entre los grupos, algo que no es sorprendente al tener en cuenta que se intentaba resaltar el éxito de los uacúsecha como conquistadores y señores supremos de la región. La tradición nahua, que 
también resalta los meritos del propio grupo, no excluye el tema de la tributación a los uacúsecha sino al parecer lo interpreta más bien como un tipo de pacto. Esta colaboración también es el argumento principal de la Memoria de Caltzin, que por su parte refleja el contenido del códice de don Domingo Catsimito: los mercaderes nahuas y los uacúsecha eran aliados militares. En este sentido la narrativa nahua y el discurso uacúsecha (contenido en la Relación de Michoacán) no son contradictorios sino más que nada probablemente constituyen versiones complementarias de los mismos acontecimientos sucedidos en las últimas décadas de la época prehispánica. El papel protagónico del grupo nahua de don Domingo en la lucha que se desarrolló en el siglo xvi para recuperar los derechos y privilegios de la capital Tzintzuntzan, podría ser un reflejo y consecuencia de la posición privilegiada de sus antepasados en la sociedad prehispánica.

Las visiones sobre el poblamiento de Michoacán y las relaciones interétnicas entre nahuas y tarascos no sólo figuran en las fuentes regionales sino también ocupan un lugar importante en las tradiciones históricas de los mexicas que en el Posclásico llegaron a ser vecinos y enemigos del señorío tarasco y de su linaje gobernante (los uacúsecha). La mayoría proviene del centro de México, sin embargo existe una versión muy interesante y poco conocida que fue recogida en la Nueva Galicia por el franciscano Fray Antonio Tello en el segundo libro de su Crónica Miscelánea de la Sancta Provincia de Xalisco, obra terminada aproximadamente en 1653 (Tello 1968, pp. 21-31).

\section{La Crónica de Tello: la fundación mexica de Tzintzuntzan- Huitzitzilan}

Aunque debe tenerse en cuenta que el tema fue tratado con mayor amplitud en el perdido e inédito primer libro de su crónica, la narración recopilada por Fray Antonio Tello se remite al origen de los mexicas o mexicanos y de su dios Huitzilopochtli en el nórdico Aztlan, lugar que el asociaba con la provincia de Aztatlán. Guiados por su deidad tutelar, pasaron por Hueyculhuacan y otros lugares para arribar al famoso «lugar de las siete cuevas» o Chicomoztoc, desde donde continuaron su viaje por territorios ya habitados por otros grupos que actualmente constituyen los estados de San Luis Potosí, Veracruz, Zacatecas, Nayarit, Jalisco y Guanajuato, fundando múltiples poblaciones a su paso. Posteriormente se dirigieron a la región de los tarascos, a que llegaron a nombrar Michoacán. Según el relato entraron por Huáscatos, Pénjamo, Numarán y Conguripo para acercarse a la Laguna de Tzintzuntzan (el actual Lago de Pátzcuaro). Los migrantes fueron bien recibidos por los tarascos y a través de Huitzilopochtli se estableció una relación de amistad que fue celebrada en una « fiesta a su concordia » que podría ser interpretada más bien como un ritual de alianza. Ante la pregunta del mencionado dios de si querían establecerse en la región, los mexicas 
respondieron con una negativa, argumentando que el entorno les parecía destemplado y montañoso. Aun así, permanecieron por el espacio de dos años, difundiendo su culto religioso entre los tarascos que antes no lo usaban. En seguida Huitzilopochtli ordenó que un grupo de los mexicas « más políticos » se apartara de los migrantes y se quedara en Tzintzuntzan-Huitzitzilan para vivir juntos con sus amigos tarascos, quienes:

[...] por ser gente inculta tenía necessidad de quien les enseñase en el gobierno de su república y en el culto de la idolatría, y pareciéndoles bien, nombraron por catzique y señor a un indio mexicano noble y de gran talento llamado Tzilantzi, el qual, con los de su familia, poblaron la ciudad de Huitzitzila, que ahora se llama Tzintzontzan, adornándola de muy fuertes $[\mathrm{y}]$ vistosos edificios, y quedaron tan confederados los mexicanos y tarascos, que nunca tuvieron disgusto, antes los mexicanos olvidaron su lenguaxe y de este catzique Tzilantzi descendieron los señores y reyes de Michoacán. (ibid., p. 30) ${ }^{13}$

Cabe agregar que los demás migrantes siguieron su itinerario por Yuririapundaro, Cuitzeo, Acambaro y Coroneo para luego dirigirse rumbo a Chiapa (actualmente Chiapa de Mota). Los mexicanos poblaron todo el occidente y se establecieron entre la población local, dando nombres nahuas a pueblos, cerros y plantas, antes de dirigirse al centro de México.

De acuerdo a la anterior narración, Tzintzuntzan o Huitzitzilan (ambos significan " lugar de colibríes ») originalmente era un asentamiento tarasco pero fue reorganizado a raíz del establecimiento de un grupo de mexicas que se aliaron con los pobladores. Estos cambios al parecer también tuvieron su propio fundamento ideológico con la introducción del culto a Huitzilopochtli (« colibrí a la izquierda »). Se creó un señorío multiétnico que consistía de tarascos y mexicas, con un gobierno cuya primera cabeza fue Tzilantzi ${ }^{14}$. De él descendieron todos los demás señores de Tzintzuntzan-Huitzitzilan. La lengua que hablaban era el tarasco ya que el mexicano (náhuatl) se perdió.

Igual que la Relación de Michoacán, el Lienzo de Jicalán, la Probanza de Tetlama y la Memoria de Caltzin, la narración registrada por fray Antonio Tello se refiere a la antigüedad de la presencia nahua en la parte central de Michoacán, que antecede la creación del señorío tarasco o uacúsecha. Mientras que los demás - todas fuentes de la propia región - resaltan que este grupo nahua claramente se distinguía de los tarascos (en cuanto a lengua y cultura), la visión recogida por Tello más bien enfatiza que los nahuas primero transmitieron ciertas características culturales a los tarascos (sobre todo en cuanto a la política y religión) pero después perdieron su lengua y quedaron completamente asimilados por el grupo dominante. En esta versión tardía se niega o por lo menos se desconoce la presencia de una fuerte población nahua en Tzintzuntzan-Huitzitzilan al final del Posclásico tardío y la mayor parte del siglo xvi.

Otro elemento que llama la atención es que en la narración de Tello los tarascos claramente necesitaban el apoyo y la instrucción de los migrantes para 
poder desarrollarse y fundar su propio señorío: es decir, los fundamentos de la cultura tarasca son considerados como esencialmente mexicas. De esta manera, los vecinos y adversarios del señorío, que en realidad nunca lograron conquistar a los tarascos, desarrollaron su propia tradición histórica y visión del mundo en que establecieron una relación directa - incluso de parentesco - con el grupo dominante en Michoacán y al mismo tiempo expresaron su propia supremacía y caracterizaron a los tarascos como un grupo de cultura inferior. Este interesante discurso no sólo se encuentra presente en la versión que recopiló Tello sino también aparece en varias narrativas del Valle de México que igualmente plantean una relación directa entre la ocupación del territorio michoacanense y el origen de los mexicas. Cabe agregar que el mencionado fraile nos especifica que la información le fue proporcionada por don Francisco Pantecatl, hijo del cacique Xonacatl que al momento de la llegada de los españoles gobernaba el asentamiento y jurisdicción de Acaponeta (actualmente correspondiente a un pueblo del Estado de Nayarit): « Don Francisco Pantecatl la dejó escripta a sus hijos y descendientes por memoria, diciendo que lo que en ella refiere lo oyó decir y contar a sus antepasados y abuelos » (Tello 1968, p. 33). Sin embargo, Tello también tenía conocimiento de las propias tradiciones históricas del centro de México, cuyos contenidos le parecieron muy similares a lo que había registrado en la región del occidente ${ }^{15}$. Por lo anterior, aunado al hecho de la redacción tardia de la obra, es probable que el franciscano haya intentado interpretar y compaginar datos de diversas fuentes (Weigand y Weigand 1996, pp. 102-103). Además, conviene tener en cuenta que en la dificultosa colonización del occidente, llevada a cabo aproximadamente un siglo antes de la redacción de su crónica, había participado una amplia gama de aliados indígenas de los españoles, entre ellos grupos de tarascos, mexicas y tlaxcaltecas, que introdujeron sus propias formas de organización, lenguas y visiones del pasado (ibid., pp. 102-126; Álvarez 2008).

\section{El poblamiento de Michoacán en las tradiciones históricas del centro DE MÉxico}

Igual que la variante registrada por Tello, algunas narraciones del centro de México incluyen a la ocupación de Michoacán en una serie de sucesos que ocurrieron durante la larga migración de los mexicas que inició en el mítico Aztlan (o Chicomoztoc) y que terminó con la fundación de México-Tenochtitlan. La fuente que presenta la versión más extensa de estos acontecimientos, es la Historia de las Indias de la Nueva España e islas de Tierra Firme (1581), elaborado por Fray Diego Durán ${ }^{16}$ :

Es de saber que los mexicanos, los que agora son tarascos y habitan la provincia de Mechoacan, y los de la provincia de Malinalco, todos eran de una congregación o 
parcialidad y parientes, y salieron de aquella séptima cueva, debajo del amparo de un dios que los guiaba y todos hablaban una lengua. Llegados a aquel lugar de Pátzcuaro, viéndole tan apacible y alegre, consultaron a su dios los sacerdotes y pidiéronle que, si no era aquel el lugar que les tenía prometido y habían de fuerza pasar adelante, que al menos tuviese por bien de que aquella provincia quedase poblada.

El dios Huitzilopochtli respondió a sus sacerdotes en sueños que él era contento de hacer lo que le rogaban y que el modo sería, que todos los que entrasen en una laguna grande que en aquel lugar hay a se lavar, como ellos lo tienen de costumbre y uso, así hombres como mujeres, que después de entrados, se diese aviso a los que afuera quedasen que les hurtasen la ropa, así a ellos como a ellas, $y$, sin que lo sintiesen, alzasen el real y se fuesen con ella y los dejasen desnudos.

Los mexicanos, obedeciendo el mandato de su dios, estando los de la laguna embebecidos en el contento del agua, sin ningún detenimiento alzaron el real y partieron de allí, tomando la vía que su dios les señaló.

Después de haberse lavado con mucho contento los que estaban en la laguna, salieron de ella y, buscando su ropa para cubrirse, no la hallaron, y entendiendo ser burla que los demás les hacían, vinieron al real donde habían dejado la demás gente, y halláronlo solo y sin persona que les dijese hacia qué parte había tomado la vía, y viéndose así desnudos y desamparados y sin saber a dónde ir, determinaron de quedarse allí y poblar aquella tierra.

Y cuentan los que dan esta relación que como quedaron desnudos en cueros, así ellos como ellas, y lo estuvieron mucho tiempo, que de allí vinieron a perder la vergüenza y traer descubiertas sus partes impúdicas y a no usar bragueros ni mantas los de aquella nación, sino unas camisas largas hasta el suelo, como lobas judaicas, el cual traje yo lo alcancé y hoy día entiendo se usa entre los macehuales. (Durán 1967, tomo II, p. 30)

De acuerdo a la narración registrada por Durán, una parte de los migrantes mexicas fue obligada a quedarse en Pátzcuaro (Michoacán) mediante un engaño por parte del dios Huitzilopochtli que implicaba el robo de ropa ${ }^{17}$. Este suceso incluso obligó a los abandonados a cambiar su vestimenta y de esta manera distinguirse de quienes siguieron su ruta rumbo al centro de México. El jesuita Juan de Tovar, en su Relación del origen de los Yndios que havitan en esta Nueva España segúm sus Historias (1587), se remite a los mismos sucesos, aunque de manera más breve. Sin embargo, en su versión se enfatiza el enojo de los migrantes que se quedaron atrás y se agrega que esta fue la razón del cambio en el modo de vestirse:

Los otros, que no advirtieron el engaño con el gusto de vañarse, quando salieron y se hallaron despojados de sus ropas y assí burlados y desanparados de los otros, quedando muy agraviados, por negarlos en todo, de propósito mudaron el vestido y el lenguaje y assi se diferenciaron de su nación mexicana. (Tovar 1972, p. 14)

El Códice Ramirez (segunda mitad del siglo XvI) y la Historia natural y moral de las Indias (1590), esta última del jesuita Joseph de Acosta, hablan del mismo tema y muestran muchas semejanzas con el trabajo de Tovar pero suben de tono en cuanto a los agravios sufridos por los abandonados quienes « [...] quedaron 
muy sentidos y quejosos, y por declarar el odio que les cobraron, dicen que mudaron traje y aun lenguaje " (Acosta 1962, pp. 325-326) ${ }^{18}$. Según Acosta estos acontecimientos incluso pudieron haber influido en la relación de enemistad que existía entre los tarascos (a quienes el se refiere como mechoacanenses) y los mexicas, lo que fue retomado por el dominico Gregorio García (1607) en su Origen de los indios del Nuevo Mundo e Indias Occidentales (García 1981, pp. 325 326). Un poco más de siglo y medio después, la información de ambos autores llegó a formar la parte medular de las reflexiones sobre el mismo tema por parte del franciscano Pablo Beaumont, en su Crónica de la provincia de los Santos Apóstoles San Pedro y San Pablo de Michoacán, obra que concluyó aproximadamente en 1778 (Beaumont 1932, tomo II, pp. 40-44). Aunque el cronista dieciochesco también conocía el trabajo de fray Antonio Tello, no lo cita en sus comentarios sobre el origen de los michoacanos. Sin embargo, en el mismo contexto sí se refiere brevemente a la Crónica (1649) de fray Alonso de la Rea, a quien sigue cuando observa que el topónimo Tzintzuntzan-Huitzitzilan tiene su origen en el nombre de Huitzilopochtli, el dios que guió a los migrantes (Rea 1996, p. 74). Cabe agregar, aunque Beaumont no señala nada al respecto, que de la Rea conoció el Lienzo de Jicalán cuando éste todavía se encontraba resguardado en Jucutacato y pensaba que el documento trataba del origen de los tarascos y de su traslado a Michoacán, donde se separaron de los grupos aztecas (uno de ellos eran los mexicas) con quienes habían salido de Chicomoztoc, lugar que para el religioso o sus fuentes equiparaba a Aztlan. En cuanto a los detalles de la migración y poblamiento de la región, menciona y critica la Crónica agustina de Juan de Grijalva (1624) en que no se atribuye la división de los michoaques al engaño orquestado por Huitzilopochtli sino más bien al cansancio y a la imposibilidad de continuar en el camino por parte de ancianos, niños y enfermos (ibid., pp. 71-72; Grijalva 1985, p. 86).

Aunque también Fernando Alvarado Tezozomoc, en su Crónica Mexicayotl (1609), se refiere al poblamiento forzoso de Michoacán, sus comentarios son muy breves y no incluyen ninguna mención de una posible reacción por parte de la facción que fue obligada a quedarse (Tezozomoc 1992, pp. 27-28). Al mismo tiempo llama la atención que este autor - o más bien sus fuentes originales - al parecer une el referido suceso con lo que en otros documentos arriba señalados (Durán, Tovar, Acosta y el Códice Ramírez...) es el siguiente episodio de la migración: la separación obligada en Malinalco de la diosa Malinalxochitl, la hermana del dios Huitzilopochtli. Esto es especialmente notorio y explícito en la Crónica Mexicana (1598), también de la mano de Tezozomoc, que nos dice lo siguiente:

[...] llegaron a Malinalco, hombres y mujeres comenzaron a retozar en el agua de gran contento, adonde es ahora Pátzcuaro, y los otros mexicanos, viniendo cantidad de mujeres, se quedaron, les tomaron por fuerza sus mantas y atajador de sus vergüenzas Maxtli, a las mujeres sus huipiles y naguas, de manera que los varones quedaron sin 
taparse sus vergüenzas y las mujeres con la prisa hicieron a manera de capisayo o capote vizcaíno, que llaman ellos Zicivilli, que hoy día los traen puestos por el calor que allí hace: los varones usaban el traje a manera de huepil, con su hombro labrado. La hermana mayor que allí quedó con ellos llamada Malinalxoch, que se intitulaba ser hermana del dios Huitzilopochtli, venía con ellos, después de haber consolado a los que quedaron en la parte de Mechoacan [...]. (Tezozomoc 1944, pp. 9-11) ${ }^{19}$

En esta versión, la separación de Malinalxochitl en Malinalco se mezcla completamente con el poblamiento en Pátzcuaro y a la hermana de Huitzilopochtli se le asocia directamente con Michoacán. La relación parece aún más fuerte si tomamos en cuenta que es ella quien consola a las personas abandonadas en la zona del lago, que sufrieron el engaño de Huitzilopochtli.

De acuerdo a la Crónica Mexicayotl, después de que Malinalxochitl quedara separada de los migrantes mexicas, parió a un hijo llamado Copil, cuyo padre era Chimalcuauhtli, rey de Malinalco ${ }^{20}$. Al crecer, el vástago se enteró de que su madre fue dejada en el camino y planeó asesinar al responsable, su tío Huitzilopochtli, así como a sus padres y seguidores. Sin embargo, el hermano de Malinalxochitl se dio cuenta de que su sobrino le andaba buscando para matarlo y decidió no esperar sino tomar la iniciativa y liberarse de su poderoso y aguerrido familiar. El enfrentamiento entre ambos terminó con la muerte de Copil, cuyo corazón fue extraído por Huitzilopochtli quien encargó a un sacerdote que se lo llevara para arrojarlo a un lugar de tules o carrizal (Tezozomoc 1992, pp. 39-44). Más adelante en el relato se comenta que este lugar fue elegido por el mismo dios para la fundación de la ciudad de México-Tenochtitlan:

[...] allá nació el corazón de Copil, ahora lo llamamos tenochtli (tuna dura) y pues allá estaremos, guardaremos, esperaremos, nos reuniremos con la diversa gente, nuestro pecho, nuestra cabeza, nuestra flecha, nuestro escudo con lo que les veremos a todos cuantos yacen en derredor nuestro, todos los conquistaremos, apresaremos, por esto estará nuestro poblado México Tenochtitlan, el lugar de gritar del águila, su lugar de desplegarse, el lugar de comer del águila, y el lugar de volar del pez, y el lugar de destrozar la serpiente, México Tenochtitlan [...]. (ibid., p. 64)

El mismo episodio es referido por Diego Durán (1967, tomo II, p. 38), Juan de Tovar (1972, p. 22), el Códice Ramírez... (1944, p. 31) y Joseph de Acosta (1962, p. 327), aunque los primeros tres agregan que en el mismo lugar de fundación nacieron algunas fuentes de agua caliente que se llamaban Acopilco, que según ellos quiere decir « el agua de Copil».

$\mathrm{Si}$ bien las obras señaladas en párrafos anteriores muestran considerables semejanzas en cuanto a su estructura y contenido general, al mismo tiempo evidencian una amplia variación en cuanto a detalles. Ambas características tienen su origen en una compleja combinación de factores. Debe considerarse que en el crisol multiétnico que era el centro de México, existían e incluso competían varias tradiciones históricas que se insertaban en el mismo substrato cultural 
mesoamericano y que por lo tanto tenían una estructura común, aunque al mismo tiempo mostraban variaciones que frecuentemente estaban relacionadas con la continua necesidad de enfatizar la identidad del propio grupo frente a los demás habitantes de la región. Cualquier cambio en la situación geopolítica sin duda requería de ajustes en los discursos legitimadores, lo que también contribuía a la característica dinámica de las tradiciones históricas. Un último punto, de suma importancia, es el hecho de que todas las narraciones sobre el origen y migración de los mexicas (lo mismo obviamente es aplicable al caso de los tarascos), fueron registradas a partir de la conquista española. A pesar de sus probables contenidos prehispánicos, es innegable que hayan experimentado muchas transformaciones coloniales (Castañeda de la Paz 2008a). En este sentido también conviene llamar la atención sobre los procedimientos de los diversos cronistas de la época colonial, quienes generalmente emplearon textos de sus antecesores o contemporáneos, no sólo copiando información de manera literal sino también recurriendo a la combinación e interpretación de los diversos contenidos.

A manera de ejemplo hay que mencionar sobre todo el enigmático caso de la llamada Crónica $X$, fuente perdida en que se basaron Diego Durán y Fernando Alvarado Tezozomoc. La obra del primero luego constituyó la fuente para Juan de Tovar quien fue consultado por Joseph de Acosta, autor que por su parte fue citado por otros (Barlow 1945; Peperstraete 2007, p. 47). La inclusión del tema de la separación forzada de los michoaques del grupo mexica en la Laguna de Tzintzuntzan (o Pátzcuaro) al parecer puede considerarse una de las características distintivas de la mencionada Crónica X $X$ ue fue posteriormente copiada - de manera tanto directa como indirecta - por otros cronistas. Aunque no cabe duda que debido a su continua difusión llegó a constituir una tradición histórica de impacto considerable, no debe perderse de vista que originalmente coexistía con otras tradiciones, una de las cuales no hace ninguna referencia al episodio michoacano. Esto es el caso del Códice X (también llamado Crónica Y), postulado como la fuente pictográfica que dio origen a la Tira de la Peregrinación, Códice Aubin y otros textos que igualmente se refieren a la migración mexica (Castañeda de la Paz 2008a, pp. 158-166; 2008b).

Al comparar las fuentes directamente asociadas a la Crónica $X$, llama la atención que la Crónica Mexicana de Tezozomoc claramente parece mezclar dos episodios separados en uno sólo, especificando que Malinalxochitl fue abandonada junto con el grupo que pobló en Pátzcuaro. Por supuesto se podría sugerir que el autor o sus fuentes más antiguas simplemente se hayan equivocado al identificar a Malinalco y Pátzcuaro como un solo lugar en Michoacán, teniendo implicaciones correspondientes para los sucesos relacionados con ambos topónimos (Castañeda de la Paz 2008a, pp. 167-168). Sin embargo, también es posible que en la crónica de Tezozomoc se hayan combinado tradiciones históricas diferentes: una en que Malinalxochitl estaba asociada exclusivamente con Malinalco y otra en que la hermana de Huitzilopochtli tenía una fuerte conexión 
primaria con Michoacán. Lo anterior cobra importancia al considerar otras dos narrativas importantes: las Relaciones originales de Chalco Amaquemecan de Domingo Francisco de San Antón Muñón Chimalpahin Quauhtlehuanitzin (aproximadamente 1607-1637) y sobre todo la Historia de los Mexicanos por sus pinturas que quizá es atribuible a Fray Andrés de Olmos y - si esto fuera correctotendría una fecha muy temprana (aproximadamente 1533). La tercera Relación de Chimalpahin menciona que Malinalxochitl se había separado de los mexicas en Pátzcuaro pero que después fue a establecerse en Malinalco (Chimalpahin 1998 , p. 183) ${ }^{21}$. La segunda obra cuenta como en el contexto de su migración desde Aztlan, los mexicas se dirigieron a Cuauhtitlan cuando los chichimecas - que residieron en este lugar - les quitaron una mujer y se la llevaron a Michoacán, agregando que «[...] de ella proceden todos los de Michuacan, porque antes eran chichimecas ». Esta mujer, cuyo nombre no es mencionado, tuvo un hijo que se llamaba Copil (Garibay 1979, pp. 45, 48). Este último fue sacrificado y su corazón llegó a indicar el lugar de fundación de MéxicoTenochtitlan, sucesos que son descritos de la siguiente manera:

Y porque arriba hemos dicho que estando aquí en Chapultepec fue sacrificado un hijo de la mujer que los chichimecas tomaron para llevar a Mechuacan, de donde proceden todos los de Mechuacan, dicen en este paso que este hijo de la dicha mujer vino de Mechuacan a ver a los mexicanos y como le quisieron sacrificar, dijo que no había de ser sacrificado sino en Mechuacan, donde estaba su madre. Y sobre ello hizo armas por mandado de Huitzilihuitl con Cuauhtliquetzin, y fue vencido, y por esto fue sacrificado, y el corazón fue enterrado do dijeron Tenuchtitlan y después fue fundada esta ciudad de México en aquella parte, y la cabeza la enterraron en Tlachtonco. (ibid., p. 49)

Más adelante en el relato se agrega que fue Huitzilpochtli quien dio la orden de enterrar el corazón del sacrificado y escogió el lugar específico donde más tarde sería su morada, refiriéndose a México-Tenochtitlan (ibid., p. 51).

Al parecer la Historia de los mexicanos por sus pinturas se refiere a la misma separación de Malinalxochitl de los mexicas y al posterior sacrificio de su hijo Copil que mencionamos a partir de otras obras, aunque en este caso claramente se especifica la identidad michoacana de la hermana de Huitzilopochtli y se le considera la madre de todos los pobladores de aquella región. Es posible que este relato haya formado parte de una tradición histórica distinta de la que caracteriza a Malinalxochitl como malinalca e influyó en una(s) de las fuentes que constituyeron la base para la tercera Relación de Chimalpahin y la Crónica Mexicana de Tezozomoc pero que, al parecer, no fueron recogidas por otros de los cronistas $\operatorname{conocidos}^{22}$. En estas visiones no se omite el parentesco entre mexicas y michoaques sino al parecer se amplia y se resalta aún más el ya referido argumento de la superioridad de la facción mexica de Huitzilopochtli. Además del engaño de quienes fueron abandonados en Pátzcuaro, se agrega el vencimiento y sacrificio de un personaje cuya madre hechicera era considerada michoacana, extrayendo 
su corazón y enterrándolo donde posteriormente se llegó a construir la capital tenochca ${ }^{23}$.

Las fuentes que se han mencionado no son las únicas que incluyen visiones sobre el poblamiento mexica de Michoacán pero sí constituyen los ejemplares que más extensamente se refieren a este tema y sobre todo mencionan las razones y acciones concretas que llevaron a que determinadas facciones se apartaran del grupo de migrantes. Fernando de Alva Ixtlilxóchitl, en su Sumaria relación de la historia general de esta Nueva España (1625), no sólo observa muy someramente que los mexicas peregrinaron muchos años por tierras michoacanas y que algunos de ellos se quedaron en la región sino, además, añade que esta información se encuentra confirmada por « las historias de los reyes de Michuhacan », fuentes no identificadas que el llegó a conocer probablemente a través de Constantino Huitzimengari, nieto del último rey uacúsecha Tzintzicha Tangaxoan que a principios del siglo xvII residía en el centro de México, específicamente en Coyoacán, Xochimilco y Texcoco (Ixtlilxóchitl 1985, tomo I, p. 533; Monzón, Roskamp y Warren 2009, pp. 47-48) ${ }^{24}$. Seguramente se trataba de la propia tradición histórica de los uacúsecha, de la cual una versión parcial quedó registrada en la ya mencionada Relación de Michoacán. Cabe agregar que la primera parte perdida de esta obra incluía precisamente el tema del origen de los uacúsecha que empezó con su creación por parte de los dioses (Alcalá 2000, pp. 330, 613). Es posible que también haya abarcado la sección inicial de la peregrinación del grupo, incluyendo su salida de algún lugar de creación, especialmente si se considera que su llegada al norte de Michoacán y su posterior traslado al centro de la región, constituyen el punto de partida de la segunda parte de la fuente ${ }^{25}$. Esta última, como ha sido señalado acertadamente por varios autores, muestra claras semejanzas con los relatos de migración de otros grupos mesoamericanos, en especial los del Valle de México ${ }^{26}$. Además, en la Descripción de la Ciudad y Provincia de Tlaxcala (1583-1585), cuyo autor fue Diego Muñoz Camargo, se menciona que los propios tarascos dijeron haber salido de las siete cuevas de Chicomoztoc (Martínez Baracs 2005, p. 53; Muñoz Camargo 1999, p. 120). Una posible representación de este lugar de origen (una cueva que consiste de siete rocas o compartimentos y que está ubicado tras un río o incluso en una isla) se encuentra precisamente en un escudo de armas (Figura 3), otorgado a la Ciudad de Tzintzuntzan hacia 1593 (Roskamp 2002, p. 245).

Además de la Sumaria relación de Ixtlilxóchitl, hay otras fuentes coloniales que brevemente se remiten al poblamiento de Michoacán en el contexto de los relatos de migración. Estos ya no mencionan el tema de la subdivisión de los mexicas sino plantean que los grupos ya estaban separados y que tenían su propia identidad en su lugar de origen (Aztlan, Chicomoztoc, etcétera), de donde incluso salieron de manera individual. En términos generales se presenta considerable variación en cuanto al nombre del lugar de partida, el orden de salida de los diversos grupos étnicos, la ruta y duración de sus migraciones e inclusive la 


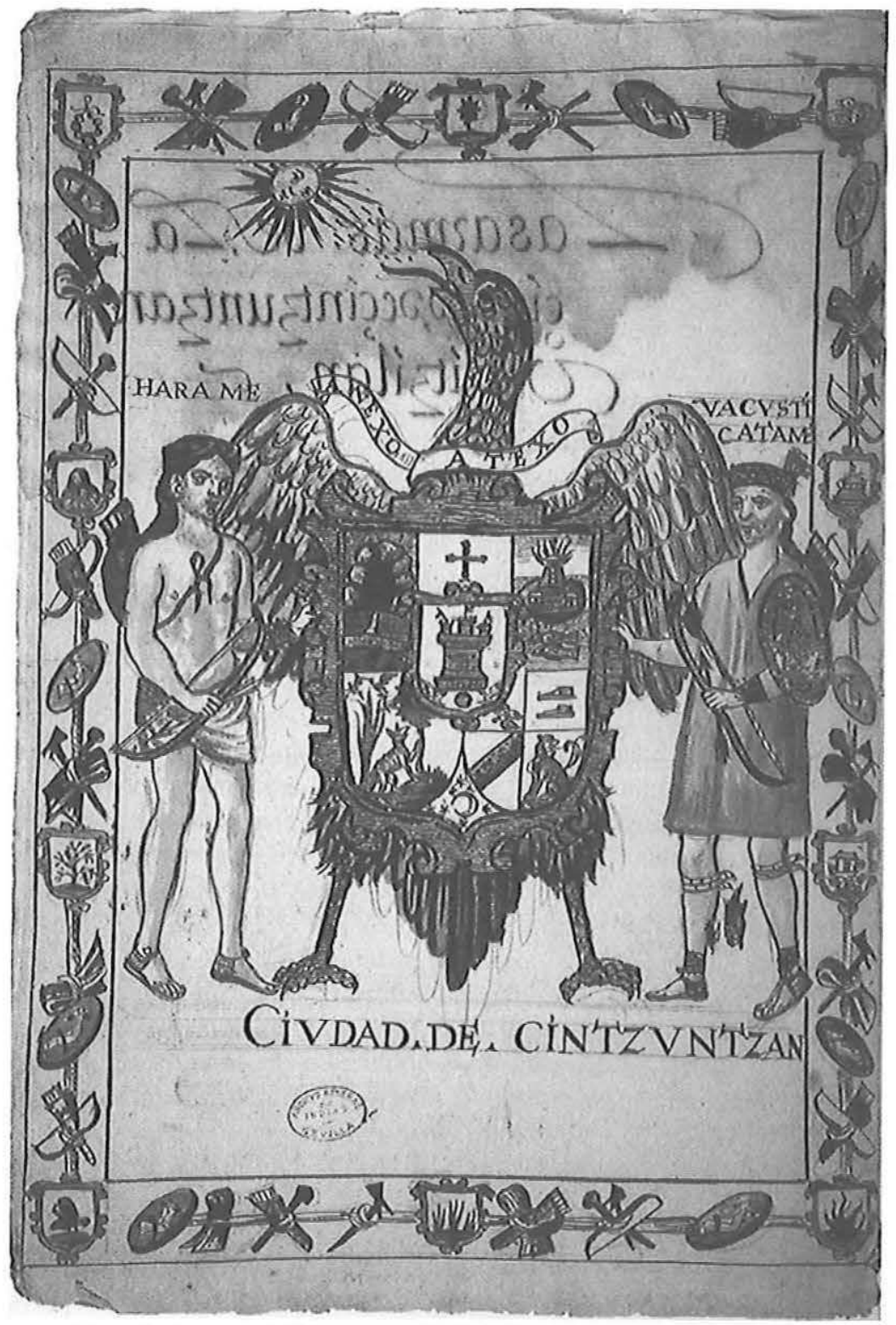

Fig. 3 - El escudo de armas de Tzintzuntzan-Huitzitzilan, 1593-1595 (Gobierno de España. Ministerio de Cultura. Archivo General de Indias, Sevilla, Escudos y Arboles Genealógicos de México, número 168). 
identificación de sus líderes y dioses patronos. Por ejemplo, según la Historia General de las cosas de Nueva España del franciscano Fray Bernardino de Sahagún (1577), los michoaques fueron guiados por un señor que se llamaba Amimitl, " flecha de agua », quizás una referencia al destino del grupo y uno de sus principales modus vivendi: la pesca en el Lago de Pátzcuaro (Sahagún 1989, volumen II, p. 675). Tampoco se puede excluir la posibilidad de que Amimitl sea al mismo tiempo precisamente una deidad, sobre todo si tomamos en cuenta la información de la Historia de los Mexicanos por sus pinturas que menciona el mismo nombre como dios de los migrantes y posteriores pobladores de Cuitlahuac, especificando que era « [...] una vara de Mixcoatl, al cual tenían por dios, y por su memoria traían aquella vara » (Garibay 1979, p. 40). En los Anales de Tlatelolco (aproximadamente 1540) se establece una asociación parecida de los migrantes michoaques (aquí también referidos como cuaochpane) con el agua, al mencionar que su líder se llamaba Teoatl que significa « agua sagrada » (Anales de Tlatelolco 1980, p. 32).

Aunque el Códice Telleriano-Remensis al parecer no se refiere a su poblamiento, Michoacán (representado mediante el glifo del altepetl con un pescado encima) sí aparece como un lugar importante en la ruta de migración de los mexicas, donde los últimos se enfrentaron violentamente a los michoaques quienes ya estaban establecidos en la región (Figura 4). Mientras que los mexicas son representados por medio de un personaje chichimeca (cazador-guerrero con piel animal, arco y flecha), la contraparte michoaque - que se encuentra herida se distingue por su túnica larga de color blanco, un adorno de plumas en la cabeza, así como un estandarte o bandera (también con plumas). Como ya se ha señalado arriba, el tema de la particular vestimenta juega un papel en varias tradiciones históricas que se remiten a los pobladores de Michoacán. Sin embargo, es la única vez que en el mismo contexto se refiere a un encuentro bélico en la propia región, si bien no queda claro si se trataba de una conquista por parte de los mexicas o más bien un intento de forzar su paso por tierras michoacanas. Sea como fuera, el discurso central no parece diferir de otras fuentes ya que claramente se resalta la superioridad militar de los mexica y se representa a los michoaques como un grupo derrotado e inferior (Quiñonez Keber 1995, pp. 54, 205).

Finalmente, es importante resaltar que el poblamiento de Michoacán no sólo figura en tradiciones históricas locales y vecinas (occidente y centro de México) sino también aparece en las visiones del pasado de un grupo geográficamente más distante, conformado por los tlaxcaltecas. En la Descripción de la Ciudad y Provincia de Tlaxcala (1584) de Muñoz Camargo (1999, pp. 134-137), se menciona que los tarascos fueron los primeros en salir de Chicomoztoc, en búsqueda de las tierras prometidas para establecer sus asentamientos ${ }^{27}$. Al tener que atravesar un estrecho de mar o río, los hombres quitaron sus bragueros (o taparrabos) para atar troncos de madera y de esta manera poder fabricar unas 


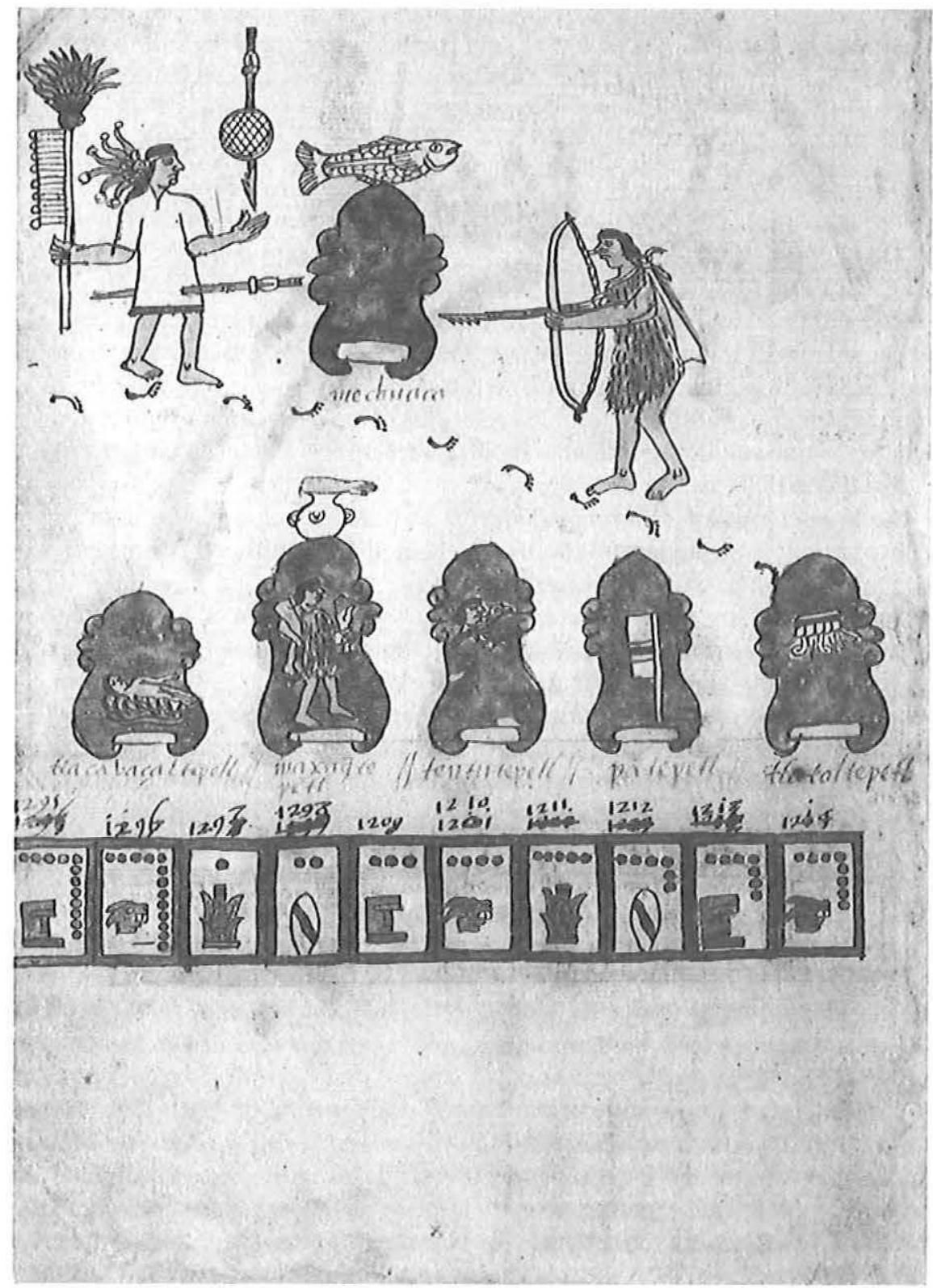

FIG. 4-El paso de los mexicas por Michoacán según el Codex Telleriano Remensis (imagen reproducida con permiso de la Bibliothèque Nationale de France). 
balsas. La pérdida de la vestimenta masculina los obligó a utilizar los huipiles de sus mujeres, los cuáles se convirtieron en su prenda típica:

$\mathrm{Y}$ ansí, quedaron con esta costumbre en memoria de aquel pasaje, donde jamás perpetuam[en]te los dichos tarascos se pusieron bragueros ni dejaron de traer los huipiles de sus mujeres, ni, menos, sus mujeres las traían ni ponían, en recordación y mem[ori]a de su peregrinación y pasaje. Y ansí, como éstos fuesen los prim[e]ros que pasaron, vinieron a poblar las prov[inci]as de Mechhuacan adonde después de muy cansados pararon, hallando aquellas tierras muy a su propósito, y conforme a su calidad y costumbres. (Muñoz Camargo 1999, pp. 136-137; 1998, p. 67)

Es interesante observar que el tema de la vestimenta también aparece en varias fuentes mexicas que se mencionaron en párrafos anteriores aunque en la variante tlaxcalteca la explicación para el peculiar hábito tarasco es distinta y no asociada al robo de la ropa masculina sino a la construcción de balsas para cruzar un mar o río: es decir, no fue consecuencia de un engaño, sino de la voluntad expresa de los tarascos (aquí no se habla de michoaques) en querer adelantarse en su ruta migratoria. Al parecer, se trata de una visión menos negativa en que se enfatiza la fortaleza y perseverancia de los pobladores de Michoacán, implicando un contraste con diversos discursos generados en el centro de México ${ }^{28}$. En cuanto a su origen, conviene recordar que como aliados de los conquistadores españoles, los tlaxcaltecas llegaron a tener una presencia en muchas regiones y por lo tanto entraron en contacto con una gran diversidad de otros grupos nativos. Sus experiencias pudieran haber influido directamente en sus propias visiones del entorno geográfico y de sus habitantes, como podría ser el caso de su opinión sobre los tarascos que ellos llegaron a conocer personalmente en el ya mencionado contexto colonial, tanto en Michoacán como en campañas en la Nueva Galicia.

\section{Comentarios finales}

Según su propia tradición histórica, una versión parcial de la cual quedó plasmada en la Relación de Michoacán, los uacúsecha llegaron a la región cuando ésta ya estaba poblada por otros grupos tarascos y por gente nahua. La antigua presencia de los últimos se encuentra también expresada en el Lienzo de Jicalán y en la Probanza de Tetlama, documentos que pertenecen a la tradición histórica del mismo grupo nahua. Las tres visiones del pasado claramente cumplen fines de legitimación y constituyen una mezcla compleja de registros de determinados sucesos, representaciones cosmológicas, así como símbolos religiosos y políticos. Resaltan el devenir y, por ende, la identidad del propio grupo, dedicando relativamente poca atención (por lo menos en las versiones existentes) a los demás grupos que habitaban el entorno directo o más lejano. Los nahuas pusieron 
énfasis en la antigüedad de su llegada y de sus derechos a recursos naturales en la Tierra Caliente, especificando que después establecieron un pacto voluntario con los señores uacúsecha, ofreciéndose como tributarios. Los uacúsecha, por su parte, ampliamente remarcaron su propio éxito como conquistadores recién llegados que en poco tiempo alcanzaron a dominar toda la región y sus habitantes, incluyendo a los nahuas.

La Relación... al parecer contiene información que indirectamente podría referirse a la presencia prehispánica de nahuas en la capital uacúsecha de Tzintzuntzan-Huitzitzilan. Se trata sobre todo de los escasos datos (esparcidos en la fuente) acerca de la identidad de los antiguos pobladores del lugar que adoraban a Xaratanga y después huyeron a Tariaran. Si se llegara a comprobar la hipótesis del fuerte sustrato nahua y su asociación al culto de la mencionada diosa, implicaría que al conquistar a Tariaran y ocupar a TzintzuntzanHuitzitzilan, los uacúsecha vencieron a los nahuas y asimilaron su tradición religiosa para incorporarla a su propia religión de estado (cuya máxima divinidad era Curicaueri). Si bien en este caso se hablaría de una derrota de los nahuas, al mismo tiempo se indicaría la importancia crucial de su antigua sede y culto como - respectivamente - lugar y símbolo de poder en la región. Las anteriores reflexiones cobran mayor relevancia a la luz del descubrimiento y análisis de la Memoria de Caltzin que muestra la visión de los nahuas de TzintzuntzanHuitzitzilan y su estatus como aliados de los uacúsecha, aunque no menciona el tema de su derrota sino, más bien, habla de su participación militar en la toma del mencionado asentamiento por los uacúsecha. $\mathrm{Al}$ momento de romperse el pacto entre los nahuas y uacúsecha, a partir de 1538 , los primeros se opusieron a las nuevas obligaciones tributarias que les fueron impuestas desde Pátzcuaro. Es posible que las mismas tensiones hayan influido en la Relación de Michoacán (1539-1541) que - siendo fuente uacúsecha céntrica - omite cualquier referencia directa a la colaboración con los nahuas.

Si bien el papel preciso de los nahuas prehispánicos de TzintzuntzanHuitzitzilan no queda claro, al comparar las mencionadas tradiciones históricas, sí queda confirmada su presencia en el corazón del señorío uacúsecha. Teniendo en cuenta la cercanía de los dominios tarascos, el hecho de que nunca fueron conquistados por sus adversarios indígenas, así como su carácter multiétnico y en especial la existencia de grupos nahuas, no es sorprendente ver que el tema de Michoacán y de su poblamiento también llegaron a ocupar un lugar en las tradiciones históricas e imaginario colectivo de sus vecinos del occidente y sobre todo del centro de México. Por lo general en las últimas se postula un origen común de michoaques y mexicas en el lejano Aztlan o Chicomoztoc, aunque los detalles varían de acuerdo a la fuente. En algunos relatos se menciona que ambos grupos estaban claramente separados e identificados desde el principio pero conforme a otras narraciones más bien constituyeron una sola entidad de la cual una parte se desprendió para establecerse en Michoacán. Las razones que se 
proporcionan para la separación también varían, del cansancio de una parte de los migrantes hasta el engaño cometido en contra de quienes se estaban bañando en la laguna. En cuanto a las consecuencias de la división, se encuentra una diversidad muy semejante, aunque la mayoría de las fuentes resalta el cambio de su vestimenta y de su lengua por parte de los michoaques. Sin embargo, en algunos casos se menciona el enojo de los abandonados e incluso la búsqueda de venganza, en la persona de Copil, un hijo de Malinalxochitl a quien a veces se le atribuye una identidad michoacana. El desenlace final de las tensiones implica otra muestra de superioridad de los mexicas, ya que Copil fue asesinado por Huitzilopochtli y su corazón tirado en el lugar donde posteriormente se construyó la capital México-Tenochtitlan. De esta manera, en estas tradiciones históricas los michoaques fueron ampliamente engañados y derrotados en tiempos primordiales, mucho antes de que llegaran a protagonizar sangrientas batallas en el posclásico tardío. Incluso es posible que estas narraciones, que expresan la ideología del estado, hayan constituido el elemento legitimador - y quizá hasta motivador - para los intentos de la expansión mexica hacia el señorío tarasco.

El relato registrado por Antonio Tello claramente se inscribe en la tradición mesoamericana de los orígenes y migraciones de los diversos grupos indígenas pero al mismo tiempo también muestra varias particularidades. La más significativa quizá sea que menciona cómo los tarascos ya estaban asentados en Michoacán cuando llegaron los mexicas quienes no sólo les transmitieron su cultura pero establecieron las bases para el posterior señorío tarasco. En este caso incluso se enfatiza que los líderes mexicas eran los antepasados de los reyes tarascos. Aunque pudiera corresponder a una antigua tradición prehispánica con un origen netamente occidental, tampoco puede descartarse que haya sido introducida o por lo menos influida por grupos migrantes del centro y sur de México que sirvieron como aliados de los españoles en el conflictivo proceso de la conquista y colonización de la Nueva Galicia.

Las múltiples variaciones y contradicciones señaladas en el presente texto claramente muestran el gran dinamismo de las tradiciones históricas indígenas que si bien lograron conservar sus estructuras medulares, al mismo tiempo también experimentaron cambios continuos. Estos últimos pueden corresponder a los procesos asociados con la propia transmisión de la memoria histórica por parte de los diversos actores sociales, así como a la compleja interacción entre la oralidad y la escritura. El primer punto se refiere sobre todo a las maneras concretas de trabajar de los tlacuilos nativos y de los cronistas (tanto españoles como mestizos) quienes copiaron, interpretaron e incluso hasta modificaron textos más antiguos y contemporáneos. En este sentido conviene también resaltar la intencionalidad de muchos cambios que tienen su origen en transformaciones socio-políticas que requerían de nuevos elementos de explicación y legitimación histórica del poder y de la identidad. No se puede perder de vista que la mayor parte de nuestras fuentes escritas corresponde precisamente a la época colonial, 


\begin{tabular}{|c|c|}
\hline FUENTES & Poblamiento de MichoacÁN \\
\hline \multicolumn{2}{|l|}{ Fuentes tarascas de Michoacán } \\
\hline $\begin{array}{l}\text { Relación de Michoacán } \\
(1539-1541)\end{array}$ & $\begin{array}{l}\text { La parte central de Michoacán ya estaba habitada por tarascos y } \\
\text { nahuas antes de que en el posclásico tardio se consolidara el señorío } \\
\text { tarasco o uacúsecha. Los uacúsecha arribaron tras una migración } \\
\text { desde el norte de la región (Zacapu) y lograron subyugar a los demás } \\
\text { pobladores. Aunque no se proporciona mayor información explicita } \\
\text { sobre la identidad y el papel de los nahuas, existen posibles indicios } \\
\text { (indirectos) de que parte de este grupo residia en Tzintzuntzan- } \\
\text { Huitzitzilan, la posterior capital de los dominios uacúsechas. }\end{array}$ \\
\hline \multicolumn{2}{|l|}{ Fuentes nahuas de Michoacán } \\
\hline Memoria de Caltzin (1543) & $\begin{array}{l}\text { Mercaderes nahuas colaboraron en la conquista uacúsecha y repo- } \\
\text { blamiento de Tzintzuntzan-Huitzitzilan que se convirtió en el centro } \\
\text { de gobierno. No se mencionan datos sobre la procedencia de estos } \\
\text { aliados nahuas. }\end{array}$ \\
\hline $\begin{array}{l}\text { Lienzo de Jicalán (1565) } \\
\text { Probanza de Tetlama (1577) }\end{array}$ & $\begin{array}{l}\text { Grupos de náhuatl hablantes migraron a Michoacán desde sus } \\
\text { lugares de origen en el este (Costa del Golfo) y fundaron sus } \\
\text { asentamientos en diversas partes de la Tierra Caliente, para poste- } \\
\text { riormente ofrecerse como vasallos voluntarios y tributarios de los } \\
\text { uacúsecha de Tzintzuntzan-Huitzitzilan. }\end{array}$ \\
\hline \multicolumn{2}{|l|}{ Fuentes de Jalisco/Nayarit } \\
\hline Fray Antonio Tello (1653) & $\begin{array}{l}\text { Tzintzuntzan-Huitzitzilan estaba poblado por tarascos y fue reor- } \\
\text { ganizado a raíz de la llegada de un grupo mexica que inmigró desde } \\
\text { el norte (Aztlan y Chicomoztoc), introdujo sus propias costumbres } \\
\text { e impuso un gobernante. Todas las posteriores autoridades descen- } \\
\text { dieron de este primer líder mexica, si bien perdieron su lengua } \\
\text { materna para hablar únicamente el tarasco. Una parte de los } \\
\text { migrantes no permaneció en Michoacán y continuó su viaje a otros } \\
\text { lugares del occidente y centro de México. }\end{array}$ \\
\hline \multicolumn{2}{|l|}{ Fuentes del centro de México } \\
\hline Fray Diego Durán (1581) & $\begin{array}{l}\text { Los pobladores originales de Michoacán (y por ende también de } \\
\text { Tzintzuntzan-Huitzitzilan) eran mexicas que durante su migración } \\
\text { desde su lugar de origen en el norte (Chicomoztoc) fueron forzados } \\
\text { - por el dios tutelar Huitzilopochtli - de quedarse en la región, } \\
\text { mientras que los demás integrantes de su grupo siguieron y poste- } \\
\text { riormente fundaron México-Tenochtitlan. Como los abandonados } \\
\text { fueron privados de su ropa cuando se estaban bañando en la laguna } \\
\text { de Pátzcuaro, empezaron a emplear otro tipo de vestimenta. }\end{array}$ \\
\hline $\begin{array}{l}\text { Fray Juan de Tovar (1587) } \\
\text { Códice Ramirez ( } 2^{\mathrm{a}} \text { mitad siglo xvi) } \\
\text { Fray Joseph de Acosta (1590) } \\
\text { Fray Gregorio García (1607) }\end{array}$ & $\begin{array}{l}\text { Ibid. (resumido). Los pobladores mexicas de Michoacán se enoja- } \\
\text { ron con los otros migrantes y por lo tanto no sólo cambiaron su } \\
\text { propia vestimenta y lengua (del náhuatl al tarasco) sino también } \\
\text { buscaron vengarse mediante la guerra. }\end{array}$ \\
\hline $\begin{array}{l}\text { Fray Andrés de Olmos (1533) } \\
\text { Tezozomoc (1598 y 1609) } \\
\text { Chimalpahin Quauhtlehuanitzin } \\
\text { (1607-1637) }\end{array}$ & $\begin{array}{l}\text { Ibid. (resumido). Entre los mexicas abandonados en Michoacán se } \\
\text { encontraba la hermana del dios Huitzilopochtli, llamada Malinal- } \\
\text { xochitl. Su hijo, Copil, quiso vengar la injusticia cometida por su tio } \\
\text { pero murió en el intento. Su corazón fue arrojado entre los tules, en } \\
\text { un lugar donde posteriormente se fundara México-Tenochtitlan. }\end{array}$ \\
\hline $\begin{array}{l}\text { Fernando de Alva Ixtlilxóchitl (1625) } \\
\text { El autor empleó historias de los reyes } \\
\text { de Michoacán (fuentes michoacanas } \\
\text { no identificadas) }\end{array}$ & $\begin{array}{l}\text { Antes de asentarse en el altiplano, los mexicas peregrinaron durante } \\
\text { muchos años por tierras michoacanas (mechoacanas) y algunos de } \\
\text { ellos incluso se quedaron a poblar la región. Por lo anterior, los } \\
\text { mexicas originalmente fueron llamados meciti, nombre que después } \\
\text { se convirtió en mexiti. }\end{array}$ \\
\hline \multicolumn{2}{|l|}{ Fuentes de Tlaxcala } \\
\hline $\begin{array}{l}\text { Diego Muñoz Camargo (1583-1585) } \\
\text { El autor utilizó fuentes orales taras- } \\
\text { cas (no identificadas) }\end{array}$ & $\begin{array}{l}\text { Michoacán fue poblado por los tarascos, el primer grupo en salir del } \\
\text { lugar de origen Chicomoztoc (esta parte fue confirmada por fuentes } \\
\text { orales tarascas). Durante su migración tuvieron que cruzar un } \\
\text { estrecho de mar o rio, lo que hicieron con balsas de troncos atados } \\
\text { con los taparrabos de los hombres. La pérdida de la vestimenta } \\
\text { masculina los obligó a que en adelante utilizaran únicamente los } \\
\text { huipiles de sus mujeres. }\end{array}$ \\
\hline
\end{tabular}

FIG. 5 - Tabla que resume la información sobre el poblamiento de Michoacán en las principales fuentes mencionadas en el presente artículo. 
cuando los discursos del pasado adquirieron un significado importante para que los diversos grupos indígenas aseguraran su posición, derechos y privilegios en la naciente sociedad novohispana.

Finalmente, es interesante observar que en las tradiciones históricas del Valle de México y de la Nueva Galicia se reconoce un parentesco primordial entre grupos mexicas y tarascos, pero se enfatiza que los primeros perdieron su lengua y fueron completamente asimilados por los últimos. Aunque a nivel michoacano las identidades particulares de los mencionados habitantes (tarascos y nahuas) fueron resaltadas y conservadas en sus memorias colectivas, las visiones de los vecinos del centro y occidente llegaron a considerar a todos como tarascos y michoaques, súbditos del señorío uacúsecha de Tzintzuntzan-Huitzitzilan. Sin embargo, de ninguna manera se puede descartar que estas últimas tal vez tengan su origen en una explicación de la situación previa a la toma del poder por parte de un linaje tarasco, cuando los nahuas al parecer todavía ocupaban una posición más importante. Cabe recordar una vez más que hasta las propias tradiciones históricas de los pobladores michoacanos resaltan la antigüedad de la presencia nahua en la región. Además, los nahuas de Jicalán y Tetlama claramente se identifican con el centro y oriente de México, incluso (en el caso de Jicalán) resaltan sus nexos con México-Tenochtitlan. Por lo tanto llama la atención que las diversas miradas al pasado muestran interesantes coincidencias (por lo menos en cuanto a su contenido general), lo que implica que todas no sólo sigan un modelo explicativo de índole mesoamericano (quizá la llamada ideología zuyuana) sino que probablemente también parten de un mismo núcleo de sucesos referentes al poblamiento y desarrollo socio-histórico de Michoacán en los últimos siglos antes de la conquista española. *

* Manuscrit reçu en novembre 2009, accepté pour publication en mars 2010.

\section{Notas}

1. Teniendo en cuenta que en el presente texto continuamente se estará refiriendo a TzintzuntzanHuitzitzilan, hay que aclarar que Tzintzuntzan y Huitzitzilan son sinónimos en lengua tarasca y nahua respectivamente, ambos significando "lugar de colibríes ». Sin embargo, mientras que la variante nahua ya aparece en las cartas de Hernán Cortés, hasta la fecha no hay registro de la versión tarasca de antes de 1538. Cabe agregar que por las mismas fechas también se empleaba la palabra Mechuacan ("lugar de los dueños del pescado »), tanto para referir a Tzintzuntzan-Huitzitzilan como a la laguna y al señorío completo. Para una amplia discusión al respecto, véase Martínez Baracs (2005, pp. 26-31, 34-35).

2. Un pionero en señalar el carácter multiétnico de la región, realizando un amplio estudio del mencionado lienzo y de la Relación de Michoacán, fue el gran americanista alemán Eduard Seler (1908, traducción en español publicada en 2000).

3. Para el caso michoacano conviene consultar los excelentes estudios de Michelet (1989), Arnauld y Michelet (1991), Arnauld y Faugère-Kalfon (1998). Los autores establecieron un diálogo crítico entre los datos arqueológicos y las fuentes históricas, mostrando que partes esenciales del discurso identitario de los tarascos no concuerdan con la imagen proporcionada por el estudio de su cultura material. 
4. Para una mayor discusión sobre las historias de migración de los pueblos del Valle de México, véase Navarrete Linares (2000).

5. Para información adicional sobre el conflicto y la larga lucha por recuperar la autonomía tzintzuntzeña, véase Castro Gutiérrez (2003), Martínez Baracs (2005), Roskamp (1997; 2002).

6. Una interpretación reciente de esta fuente histórica se encuentra en Espejel (2008).

7. Para reflexiones sobre el enfoque uacúsecha céntrico de la Relación... y su discurso de legitimación política, incluyendo amplias referencias a los pensamientos de otros autores, véase Martínez Baracs (2005).

8. Paul Kirchhoff interpretaba la cita de manera distinta y la empleaba para argumentar que originalmente toda la región de la laguna en el centro de Michoacán estaba habitada exclusivamente por nahuas. Esta observación llegó a constituir un elemento importante en su caracterización de la tradición histórica uacúsecha que según él resalta la conquista de los pescadores-agricultores de la laguna, todos náhuatl hablantes y seguidores de Xaratanga (a quien identifica como la diosa de la luna) por un grupo de nómadas y cazadores tarascos (uacúsecha) que adoraban a Curicaueri (el sol). Véase Kirchhoff (1940, p. 4; 1956, pp. XXVI-XXVII).

9. Aunque en la fuente no se identifica la identidad de sus habitantes, probablemente habría que agregar también el caso de Coyuca, nombre nahua de otra población del medio Balsas (Alcalá 2000, p. 524).

10. Sin embargo, en este último caso no está claro si se trata de una población avecindada apenas en la época colonial o si tenía una presencia más antigua. Sin descartar esta última posibilidad, es importante señalar que poco tiempo antes de que Alcalá terminara de redactar su crónica, grupos nahuas y tarascos de Tzintzuntzan se habían trasladado a Pátzcuaro y sus barrios. En 1573 un informante franciscano refería a que «[...] todos los indios naturales de Tzintzontza que son los naguales se vinieron a poblar al dicho sitio [Pátzcuaro] mucha cantidad dellos e otros tarascos [...] ». Según los principales Anton Acatl y Juan Olin, ambos de apellido nahua y residentes en Pátzcuaro, los barrios con población nahua eran Santiago, Santo Tomás, San Matheo, San Francisco Ajuno y Guiramangaro (véase Archivo General de Indias, justicia, legajo $178, \mathrm{n}^{\circ} 1$, ramo 2, año 1573, ff. s/n.).

11. Teniendo en cuenta que los españoles emplearon esta medida violenta para obtener mayores riquezas e información sobre un determinado camino, parece probable que el mencionado nahua era un noble cercano al dirigente uacúsecha, quizá incluso era habitante de la capital o uno de sus barrios, aunque no se especifica su lugar de residencia ni su antigüedad en la región.

12. Se puede mencionar el caso del hermano adoptivo del último rey uacúsecha Tzintzcha Tangaxoan, quien se llamaba Huitzitziltzin pero cuyo nombre en lengua tarasca fue Tashauacto (ibid., pp. 661-678). Otro ejemplo, que aparece múltiples veces en la Relación..., constituye el término cazonci que probablemente haya sido derivado del náhuatl caltzontzin y entonces es sinónimo del tarasco irecha, título que se empleaba para los reyes uacúsecha. Para una mayor discusión, véase Martínez Baracs (2005, pp. 35, 48-58).

13. Aunque desconocemos la narración original que le fue transmitida a Tello, es evidente que el franciscano interpretó su contenido de acuerdo a su propia formación y misión cristiana, descalificando la antigua religión indígena como idolatría.

14. Este antropónimo nahua parece incompleto pero es probable que esté relacionado con los nombres de la deidad tutelar y de la propia población: Huitzilopochtli e Huitzitzilan. Si esto fuera correcto, el nombre original del fundador pudo haber sido Huitzilantzi, que puede traducirse como « el noble de Huitzilan (lugar de colibries) ». El nombramiento de poblaciones de acuerdo a los antropónimos de sus fundadores es un tema muy común en las tradiciones históricas indigenas del Michoacán colonial. De acuerdo a la Relación de Michoacán (1539-1541), Tariaran fue fundado por un señor que llevaba el mismo nombre. Las Relaciones Geográficas (1579-1581) por su parte, mencionan un capitán Tiripeti que estableció el pueblo de Tiripetio. Incluso puede mencionarse el corpus de títulos de Carapan (principios del siglo XviI), que hablan del rey Carapu como fundador de la localidad. Véase Alcalá (2000, pp. 350-352), Acuña (1987, pp. 348-349), Roskamp y Lucas (1999, p. 165). 
15. En este contexto hace mención de fray Toribio Motolinia y de fray Andrés de Olmos, sin mencionar sus respectivas obras pero sí especificando que ambos autores se basaron en tablas y pinturas, « en las quales estaba[n] las historias y antigüedad de los indios ». (Tello 1968, p. 33).

16. Cabe especificar que el elemento de las fechas y cronologías concretas, así como el análisis comparativo de las fuentes completas, requiere de un estudio aparte y rebasa los objetivos del presente texto.

17. Es probable que esta tradición histórica originalmente se haya referido a la fundación de Tzintzuntzan y que la inclusión del vecino Pátzcuaro tenga su origen en los cambios geopolíticos ocurridos a partir de 1538 cuando este antiguo barrio adquirió el estatus de ciudad y capital de la provincia de Michoacán. Cabe agregar que a pesar del cambio de la cabecera, la jurisdicción más amplia seguía siendo la misma y abarcaba a todos los asentamientos de la laguna (véase arriba el apartado sobre la Memoria de Caltzin).

18. También Códice Ramírez... (1944, p. 25). Cabe agregar que el Códice Ramirez y el Mamuscrito Tovar al parecer son dos versiones de la misma Historia de Juan de Tovar (Peperstraete 2007, p. 47).

19. Cabe agregar que la Crónica Mexicayotl primero se refiere al tema del poblamiento de Pátzcuaro e inmediatamente después se remite al abandono de Malinalxochitl " en el camino », sin especificar si este último suceso ocurrió en Michoacán o en un lugar distinto (Tezozomoc 1992, pp. 27-28).

20. La Crónica Mexicana es la única fuente en que el recién nacido es llamado Cohuil, sin embargo no hace referencia a sucesos específicos asociados al personaje (Tezozomoc 1944, p. 11).

21. Además, en su Historia Mexicana o Crónica, Chimalpahin observa que la mitad de los guerreros migrantes, así como sus mujeres y niños, se quedó en Michhuacan. Por otra parte, en la Historia o Crónica con su Calendario, el autor se remite al poblamiento de Michhuacan Chiuhcnahuapan por parte de un grupo que constituía una subdivisión de los mexicas y malinalcas (Anderson y Schroeder 1997, pp. 29, 187).

22. En este contexto conviene introducir un importante matiz. Chimalpahin y Tezozomoc fueron autores contemporáneos y se ha comprobado que el primero conoció y empleó la Crónica Mexicayotl del segundo. Sin embargo, teniendo en cuenta que la asociación de Malinalxochitl con Michoacán está explícita sobre todo en la Crónica Mexicana, no se puede descartar que Chimalpahin también haya consultado esta última obra. Véase también Castañeda de la Paz (2008b, pp. 188-192, 197), Peperstraete (2007, pp. 47, 51-52).

23. Chimalpahin al parecer no establece una conexión con el episodio referente a Copil.

24. Es interesante observar que Ixtlilxóchitl (1985, tomo I, p. 533), o su fuente original, establece una relación directa entre el topónimo Michoacán (Mechuacan) y el gentilicio de los migrantes (meciti, mexiti).

25. Al parecer ambas partes conformaron una sola narración histórica que fue dividida por el cronista Jerónimo de Alcalá, quizá intentando separar los contenidos de fuerte carga religiosa (la creación, los dioses, las rituales, etcétera) de aquellos que contenian las historias de los reyes del linaje uacúsecha (genealogías, guerras, conquistas, etc.) y que por lo general contaban con una mayor aceptación entre los evangelizadores.

26. Véase Michelet (1989); Arnauld y Michelet (1991); Arnauld y Faugère-Kalfon (1998).

27. Posteriormente la información fue repetida en la Historia de Tlaxcala que vio la luz en 1592 (Muñoz Camargo 1998, pp. 65-67). La temprana salida del lugar de origen también es mencionada en una tercera obra del mismo autor, terminada entre 1588 y 1589 (Martínez Baracs, Sempat Assadourian y Ruwet 1994, p. 241).

28. En cuanto a los últimos, que se caracterizan por un tono negativo, es interesante mencionar que Munoz Camargo agrega la siguiente observación sobre la etimología del término tarascos: « Llamaron, los mexicanos, tarascos a éstos de la prov[inci]a y rei[n]o de Mechhuacan, porque traían los miembros genitales de pierna en pierna y sonando, especialm[en]te cuando corrían » (Muñoz Camargo 1999 , p. 137; 1998, p. 67). Para una amplia discusión sobre el uso de esta palabra, se recomienda la consulta de Márquez Joaquín (2007). 


\section{REFERENCIAS CITADAS}

Acosta Joseph de

1962 Historia natural y moral de las Indias en que se tratan de las cosas notables del cielo / elementos / metales / plantas y animales dellas / y los ritos / y ceremonias Ileyes y gobierno de los Indios, edición preparada por Edmundo O'Gorman, Fondo de Cultura Económica, México/Buenos Aires.

ACUÑa René (ed.)

1987 Relaciones Geográficas del Siglo xv: Michoacán, Universidad Nacional Autónoma de México, México.

AlCALÁ Jerónimo de

2000 Relación de las cerimonias y rictos y población y gobernación de los indios de la provincia de Mechuacán, Moisés Franco Mendoza et al. (eds), El Colegio de Michoacán, Gobierno del Estado de Michoacán, Zamora.

Álvarez Salvador

2008 "Conquista y encomienda en la Nueva Galicia durante la primera mitad del siglo xvI: "bárbaros" y "civilizados" en las fronteras americanas ", Relaciones. Estudios de Historia y Sociedad, XXIX (116), pp. 135-188.

Anales de Tlatelolco y Códice de Tlatelolco

1980 versión preparada y anotada por Heinrich Berlin, con un resumen de los anales y una interpretación del códice por Robert H. Barlow, Ediciones Rafael Porrúa, México.

Anderson Arthur J. O. y Susan Schroeder (eds)

1997 Codex Chimalpahin. Society and politics in México Tenochtitlan, Tlatelolco, Texcoco, Culhuacam, and other Nahua Altepetl in Central México, University of Oklahoma Press, Norman.

Arnauld Charlotte y Brigitte Faugère-Kalfon

1998 «Evolución de la ocupación humana en el Centro-Norte de Michoacán (Proyecto Michoacán, CEMCA) y la emergencia del Estado Tarasco », in Véronique Darras (ed.), Génesis. culturas y espacios en Michoacán, Centro de Estudios Mexicanos y Centro Americanos (CEMCA), México, pp. 13-34.

ARnauld Marie-Charlotte y Dominique Michelet

1991 «Les migrations postclassiques au Michoacán et au Guatemala: problèmes et perspectives ", in Alain Breton, Jean-Pierre Berthe y Sylvie Lecoin (eds), Vingt études sur le Mexique et le Guatemala (réunies à la mémoire de Nicole Percheron), Presses universitaires du Mirail, Toulouse, pp. 67-92.

Barlow Robert H.

1945 "La Crónica X: versiones coloniales de la historia de los mexica-tenochca », Revista Mexicana de Estudios Antropológicos, VII (1-3), pp. 65-87.

Beaumont Pablo

1932 La Crónica de Michoacán, Publicaciones del Archivo General de la Nación XVIII, Talleres Gráficos de la Nación, México. 


\section{Carrasco Pedro}

1969 "Nuevos datos sobre los nonoalca de habla mexicana en el reino tarasco », Estudios de Cultura Náhuatl, VIII, pp. 215-221.

\section{Castañeda de la Paz María}

2008a "Codex Azcatitlan and the work of Torquemada: a historiographical puzzle in the Aztec-Mexica sources ", Latin American Indian Literatures Journal. A Review of American Indian Texts and Studies, 24 (2), pp. 151-194.

2008b "El Códice X o los anales del "Grupo de la Tira de la Peregrinación": copias, duplicaciones y su uso por parte de los cronistas ", Tlalocan: Revista de fuentes para el conocimiento de las culturas indigenas de México, XV, pp. 183214.

\section{Castro Gutiérrez Felipe}

2003 "Tzintzuntzan: la autonomía indígena y el orden político en Nueva España », in Carlos Paredes Martínez y Marta Terán (eds), Autoridad y gobierno indigena en Michoacán. Ensayos a través de su historia, Instituto Nacional de Antropología e Historia, Centro de Investigaciones y Estudios Superiores en Antropología Social, El Colegio de Michoacán, Universidad Michoacana de San Nicolás de Hidalgo, México, vol. I, pp. 285-303.

\section{Chimalpahin Domingo}

1998 Las ocho relaciones y el memorial de Colhuacan, paleografía y traducción por Rafael Tena, Consejo Nacional para la Cultura y las Artes, Cien de México, México.

Códice Ramírez. Manuscrito del siglo xv intitulado: Relación del Origen de los Indios que Habitaban Esta Nueva España, según sus Historias

1944 Examen de la obra, con un anexo de cronología mexicana por el Lic. Manuel Orozco y Berra, Editorial Leyenda, México.

\section{Durán Diego}

1967 Historia de las Indias de Nueva España e Islas de la Tierra Firme, Editorial Porrúa, México [1581].

\section{ESPEJEL Claudia}

2008 La Justicia y el fuego: dos claves para leer la Relación de Michoacán, El Colegio de Michoacán, Zamora.

Garibay K. Angel Ma. (ed.)

1979 Teogonia e historia de los Mexicanos. Tres opúsculos del siglo XVI, Editorial Porrúa, México.

Grijalva Juan de

1985 Crónica de la orden de Nuestro Padre San Agustín en las Provincias de la Nueva España, Editorial Porrúa, México.

\section{García Gregorio}

Origen de los indios del Nuevo Mundo e Indias Occidentales, Fondo de Cultura Económica, México. 
IXtLilxóchitl Fernando de Alva

1985 Obras históricas, edición, estudio introductoria y un apéndice documental por Edmundo O’Gorman, Universidad Nacional Autónoma de México, Instituto de Investigaciones Históricas, México.

KIRCHHOFF Paul

1940 «Etnografía antigua de Michoacán », ponencia presentada el 24 y 25 de mayo, manuscrito no publicado consultado en el archivo personal de Luis Reyes García, Tlaxcala, México.

1956 «La Relación de Michoacán como fuente para la historia de la sociedad y cultura tarascas ", in Anónimo, Relación de las ceremonias y ritos y población y gobierno de los indios de la provincia de Michoacán (1541), Aguilar, Madrid, pp. XIX-XXXIII.

LÓPEZ Austin Alfredo y Leonardo López LuJÁN

1999 Mito y realidad de Zuyuá, El Colegio de México, Fondo de Cultura Económica, México.

Márquez JoAquín Pedro

2007 ¿Tarascoso P'urhépecha? Voces sobre antiguas y nuevas discusiones en torno al gentilicio Michoacáno, Universidad Michoacana de San Nicolás de Hidalgo, El Colegio de Michoacán, Gobierno del Estado de Michoacán, Universidad Intercultural Indígena de Michoacán, Grupo Kw'anískuryarhani de Estudiosos del Pueblo Purépecha, Fondo Editorial Morevallado, México.

Martínez Baracs Rodrigo

2005 Convivencia y utopía: el gobierno indio y español de la " ciudad de Mechuacan ", 1521-1580, Consejo para la Cultura y las Artes, Instituto Nacional de Antropología e Historia, Fondo de Cultura Económica, México.

Martínez Baracs Andrea, Carlos Sempat Assadourian y Wayne Ruwet (eds)

1994 Suma y epíloga de toda la descripción de Tlaxcala, Universidad Autónoma de Tlaxcala, Centro de Investigaciones y Estudios Superiores en Antropología Social, México.

Michelet Dominique

1989 "Histoire, mythe et apologue: notes de lecture sur la seconde partie de la Relación [...] de Michoacán », in Dominique Michelet (ed.), Enquêtes sur l'Amérique moyenne: mélanges offerts à Guy Stresser-Péan, Instituto Nacional de Antropología e Historia, Consejo Nacional para la Cultura y las Artes, Centre d'Études Mexicaines et Centreaméricaines, México, pp. 105-113.

Monzón Cristina, Hans Roskamp y J. Benedict WarRen

2009 «La memoria de don Melchor Caltzin (1543): historia y legitimación en Tzintzuntzan, Michoacán ", Estudios de Historia Novohispana, 40, pp. 21-55.

MuÑoz Camargo Diego

1998 Historia de Tlaxcala, paleografía, introducción, notas, apéndices e índices analíticos de Luis Reyes García, con la colaboración de Javier Lira Toledo, 
Gobierno del Estado de Tlaxcala, Centro de Investigaciones y Estudios Superiores en Antropología Social, Universidad Autónoma de Tlaxcala, México.

1999 Relaciones geográficas de Tlaxcala, presentación de Boris Berenzon Gorn y edición, prólogo, introducción y notas por René Acuña, El Colegio de San Luis, Gobierno del Estado de Tlaxcala, San Luis Potosí.

Navarrete Linares Federico

2000 Mito, historia y legitimidad politica: las migraciones de los pueblos del Valle de México, Facultad de Filosofia y Letras, Universidad Nacional Autónoma de México, Tesis de doctorado inédito, México.

\section{Peperstraete Sylvie}

2007 La " Chronique $X$ ». Reconstitution et analyse d'une source perdue fondamentale sur la civilisation aztèque, d'après l'Historia de las Indias de Nueva España de D. Durán (1581) et la Crónica mexicana de F. A. Tezozomoc (ca. 1598), Archaeopress, British Archaeological Reports International Series $n^{\circ} 1630$, Oxford.

\section{QUIÑONEZ KeBER Eloise}

1995 Codex Telleriano-Remensis: ritual, divination, and history in a pictorial Aztec manuscript, foreword by Emmanuel Le Roy Ladurie, illustrations by Michel Besson, University of Texas Press, Austin.

ReA Alonso de la

1996 Crónica de la Orden de Nuestro Seráfico Padre San Francisco, Provincia de San Pedro y San Pablo de Mechoacan en la Nueva España, Edición y estudio introductorio de Patricia Escandón, Fideicomiso Teixidor, El Colegio de Michoacán, Zamora.

\section{RosKamp Hans}

1997 "Pablo Beaumont and the Codex of Tzintzuntzan; a pictorial document from Michoacán, West México », in Maarten Jansen y Luis Reyes García (eds), Cuadernos de Historia Latino-Americama, 5, Asociación de Historiadores Latinoamericanistas Europeos (AHILA), Ridderkerk, pp. 193-245.

1998 La Historiografia Indigena de Michoacán: el Lienzo de Jucutacato y los Titulos de Carapan, Researchschool CNWS, Universidad de Leiden, Leiden.

2001 "Historia, mito y legitimación: el Lienzo de Jicalán », in Eduardo Zárate (ed.), La Tierra Caliente de Michoacán, El Colegio de Michoacán, Gobierno del Estado, Zamora, pp. 119-151.

2002 «La heráldica novohispana del siglo xvi: un escudo de armas de Tzintzuntzan, Michoacán », in Herón Pérez Martínez y Bárbara Skinfill Nogal (eds), Esplendor y ocaso de la cultura simbólica, El Colegio de Michoacán, Consejo Nacional de Ciencia y Tecnología, Zamora, pp. 227-268.

\section{Roskamp Hans y Benjamín Lucas}

1999 «Hireti Thicátame y la Fundación de Carapan: un nuevo documento en lengua p'urhépecha », Relaciones: estudios de historia y sociedad, XXI (82), pp. 159-173. 
SAHAGÚN Bernardino de

1989 Historia general de las cosas de Nueva España, introducción, paleografía, glosario y notas de Josefina García Quintana y Alfredo López Austin, Consejo Nacional para la Cultura y las Artes, Alianza Editorial Mexicana, México.

SELER Eduard

1908 "Die Alten Bewohner der Landschaft Michuacan ", Gesammelte Abhandlungen zur Amerikanischen Sprach und Alterthumskunde, III, pp. 33-156.

2000 "Los antiguos habitantes de Michoacán ", traducción de Erika Krieger, confrontación con el original alemán, introducción, corrección y notas de Francisco Miranda, in Jerónimo de Alcalá, Relación de las cerimonias y rictos y población y gobernación de los indios de la provincia de Mechuacán, Moisés Franco Mendoza et al. (eds), El Colegio de Michoacán, Gobierno del Estado de Michoacán, Zamora, pp. 139-233.

Tello Antonio

1968 Crónica Miscelánea de la Sancta Provincia de Xalisco, libro segundo, vol. I, Gobierno del Estado de Jalisco, Universidad de Guadalajara, México.

Tezozomoc Fernando Alvarado

1944 Crónica Mexicana, Manuel Orozco y Berra (notas), Editorial Leyenda, S.A., México.

1992 Crónica Mexicayotl, Adrián León (traducción), Universidad Nacional Autónoma de México, México.

Tovar Juan de

1972 «Relación del origen de los Yndios que havitan en este Nueva España según sus Historias ", in Jacques Lafaye (ed.), Mamuscrit Tovar: origines et croyances des indiens du Mexique, Akademische Druck- u. Verlagsanstalt, Graz, pp. 9-84 [1587].

Weigand Phil C. y Acelia G. de Weigand

1996 Tenamaxtli y Guaxicar: las raices profundas de la rebelión de Nueva Galicia, El Colegio de Michoacán, Secretaría de Cultura de Jalisco, Zamora. 